\title{
Síntesis de la evidencia: Guía de práctica clínica para el diagnóstico y el tratamiento de la pubertad precoz
}

\author{
M. Fernanda Castilla-Peón ${ }^{1 *}$, Margarita Torres-Tamayo ${ }^{2}$, Jessie N. Zurita-Cruz ${ }^{3}$, Blanca E. Aguilar-Herrera ${ }^{4}$, \\ América L. Miranda-Lora ${ }^{1}$, Aleida J. Rivera-Hernández ${ }^{4}$, Raúl Calzada-León ${ }^{5}$ Marco A. Morales-Pérez ${ }^{6}$, \\ Miriam M. Padrón-Martínez ${ }^{5}$, María L. Ruiz-Reyes ${ }^{5}$, Leticia M. García-Morales' ${ }^{1}$, Consuelo Barrón-Uribe ${ }^{3}$, \\ Sletza L. Arguinzoniz-Valenzuela ${ }^{5}$, Mayra C. Torres-Castañeda7, Lorena Lizárraga-Paulin7, \\ Jorge A. Núñez-Hernández ${ }^{8,9}$, Judith Cornejo-Barrera ${ }^{10}$, María T. Vidal-González ${ }^{11}$, \\ María R. Martínez-Alvarado², Elisa Nishimura-Meguro ${ }^{3}$, Luz E. Bravo-Ríos ${ }^{3}$, Eulalia P. Garrido-Magaña ${ }^{4}$, \\ José A. Orozco-Morales ${ }^{1}$, Patricia G. Medina-Bravo ${ }^{1}$ y Ninel Coyote-Estrada ${ }^{3}$
}

${ }^{1}$ Hospital Infantil de México Federico Gómez, Ciudad de México; ${ }^{2}$ Instituto Nacional de Cardiología Ignacio Chávez, Ciudad de México; ${ }^{3} \mathrm{Hospital}$ de Pediatría Centro Médico Nacional Siglo XXI, Ciudad de México; ${ }^{4}$ Sociedad Mexicana de Endocrinología Pediátrica, Ciudad de México; ${ }^{5}$ nstituto Nacional de Pediatría, Ciudad de México; ${ }^{6} \mathrm{Hospital}$ General de Zona No. 18, Playa del Carmen, Quintana Roo; ${ }^{7}$ Hospital General del Centro Médico Nacional La Raza, Ciudad de México; ${ }^{8}$ Hospital General Regional 220, Instituto Mexicano del Seguro Social, Ciudad de México; 9 Instituto Materno Infantil del Estado de México, Toluca, Estado de México; ${ }^{10} \mathrm{Hospital}$ Infantil de Tamaulipas, Ciudad Victoria, Tamaulipas; ${ }^{11} \mathrm{Hospital}$ del Niño y el Adolescente Morelense, Cuernavaca, Morelos. México

\section{Resumen}

Se realizaron tres revisiones sistemáticas para la formulación de las recomendaciones sobre diagnóstico, tratamiento y seguimiento de pacientes con pubertad precoz: intervenciones para el tratamiento de la pubertad precoz que incluyeran los desenlaces de talla final o casi final, salud mental, salud metabólica, salud ósea o éxito en el bloqueo; estudios observacionales comparativos que evaluaran desenlaces a largo plazo en sujetos con antecedentes de pubertad precoz; y por último, estudios de exactitud de prueba diagnóstica para pubertad.

Palabras clave: Pubertad precoz. Tratamiento. Diagnóstico. Revisión sistemática.

\section{Synthesis of the evidence: Clinical guideline for the diagnosis and treatment of precocious puberty}

\begin{abstract}
Three systematic reviews were conducted to formulate the recommendations on diagnosis, treatment and follow-up of patients with precocious puberty: interventions for the treatment of precocious puberty that included the outcomes of final or near-final height, mental health, metabolic health, health bone, or blockade success; comparative observational studies evaluating long-term outcomes in subjects with a history of precocious puberty; and diagnostic test accuracy studies for puberty.
\end{abstract}

Key words: Precocious puberty. Treatment. Diagnosis. Systematic review.

Correspondencia:

*M. Fernanda Castilla Peón

E-mail: fernandacastillapeon@gmail.com DOI: 10.24875/BMHIM.20000087
Fecha de recepción: 24-03-2020

Fecha de aceptación: 28-03-2020
Disponible en internet: 23-06-2020 Bol Med Hosp Infant Mex. 2020;77(Supl 1):35-40

www.bmhim.com (http://creativecommons.org/licenses/by-nc-nd/4.0/). 


\section{Análogos de la hormona liberadora de gonadotropina (aGnRH) para el tratamiento de la pubertad precoz}

\section{Metodología}

\section{Criterios de inclusión}

- Tipo de estudios: ensayos clínicos controlados con o sin aleatorización y con o sin cegamiento que evaluaran cualquiera de los desenlaces de interés. Se buscaron también estudios observacionales comparativos que evaluaran alguno de los desenlaces de interés en la edad adulta.

- Tipo de participantes: niñas menores de 8 años con crecimiento mamario (estadio de Tanner II o mayor) y niños menores de 9 años con crecimiento testicular (volumen testicular de $4 \mathrm{~cm}^{3}$ o mayor).

- Intervención: algún aGnRH de depósito (triptorelina, leuprorelina, histrelina o goserelina) con o sin cointervenciones.

- Control: sujetos que no recibieron aGnRH o que recibieron una dosis o una formulación diferente de las del grupo de intervención. En caso de que se usaran cointervenciones, ambos grupos debían haber recibido las mismas.

- Desenlaces: talla adulta o casi adulta, medidas de impacto psicológico o de calidad de vida, medidas de éxito en el bloqueo de la pubertad, medidas de salud ósea y medidas de salud metabólica.

\section{ESTRATEGIA DE BÚSQUEDA}

- Ensayos clínicos: se realizó una búsqueda en PubMed y Cochrane Library Trials Register con los términos "puberty" AND ("GnRH analog" OR "GnRH agonist" OR "gonadotropin releasing hormone agonist" OR "gonadotropin releasing hormone analog" OR "gonadotropin-releasing hormone agonist" OR "gonadotropin-releasing hormone analog" OR "leuprolide" OR "triptorelin" OR "histrelin" OR "goserelin" OR "nafarelin"). Filtro: ensayos clínicos.

- Estudios observacionales a largo plazo: se realizó una búsqueda en PubMed con los términos "puberty AND ("GnRH analog" OR "GnRH agonist" OR "gonadotropin releasing hormone agonist" OR "gonadotropin releasing hormone analog" OR "gonadotropin-releasing hormone agonist" OR "gonadotropin-releasing hormone analog" OR "leuprolide" OR "triptorelin" OR "histrelin" OR "goserelin" OR "nafarelin") AND ("adult height" OR "final height" OR "adverse events" OR "side effects" OR "safety" OR "bone" OR "metabolic" OR "lipids" OR "insulin resistance"). Filtros: clinical trial phase III, clinical trial phase IV, comparative study, observational study. También se realizó la búsqueda con los términos ("precocious puberty" [title] AND ("GnRH" OR "treatment") AND ("long term" OR "adult").

- Desenlaces psicosociales: por ser de particular interés, también se llevó a cabo una búsqueda para los desenlaces psicosociales en PubMed con los términos "Puberty, precocious" AND ("mental health" OR "quality of life" OR "psychological" OR "health risk behaviors"). Filtro: español e inglés.

\section{SELECCIÓN DE ESTUdios}

Todos los títulos y los resúmenes identificados en la búsqueda fueron evaluados por dos revisores, quienes examinaron el texto completo de todos los ensayos que potencialmente cumplían los criterios de inclusión. Se resolvieron los desacuerdos mediante discusión con un tercer revisor hasta llegar a un consenso.

\section{EXTRACCIÓN DE DATOS}

Dos revisores por estudio extrajeron los datos relevantes de los estudios en un formato diseñado previamente. Cuando hubo discordancia en la captura de datos, se discutió con un tercer revisor hasta llegar a un consenso.

\section{Evaluación de La CALIDAD DE LOS ESTUdios INCLUIDOS}

Se evaluó el riesgo de sesgo mediante la herramienta Programa de Habilidades de Lectura Crítica en Español (CASPe, Critical Appraisal Skills Programme - español) para ensayos clínicos ${ }^{1}$. Una vez considerados los rubros evaluados por este instrumento, los miembros del grupo desarrollador de la guía asignaron uno de tres niveles para la calidad (de menor a mayor): ,$-+y++$.

\section{Resultados}

\section{ENSAYOS CLÍNICOS}

Se identificaron 78 referencias en el Registro de Ensayos Clínicos de Cochrane Library y 88 referencias en PubMed hasta el 6 de marzo de 2018. Se excluyeron 30 referencias por estar duplicadas. Ocho estudios 
cumplieron los criterios de inclusión. Los estudios incluidos se describen en las tablas 1 y 2 del anexo.

\section{ESTUDIOS OBSERVACIONALES A LARGO PLAZO}

Se encontraron 104 referencias. Cinco estudios cumplieron los criterios de inclusión (Tabla 3 del anexo).

\section{ESTUdIOS SOBRE DESENLACES PSICOSOCIALES}

Se obtuvieron 81 referencias. En ninguno de los estudios se evaluó el efecto del bloqueo de la pubertad en los desenlaces psicosociales. La tabla 4 del anexo describe los estudios que se aproximan a la evaluación del efecto de la pubertad precoz/temprana en los desenlaces psicosociales.

\section{Intervenciones adyuvantes en el tratamiento de la pubertad precoz}

\section{Metodología}

\section{Criterios de inclusión}

- Tipo de estudios: ensayos clínicos controlados con 0 sin aleatorización y con o sin cegamiento.

- Tipo de participantes: niñas menores de 8 años con crecimiento mamario (estadio de Tanner II o mayor) y niños menores de 9 años con crecimiento testicular (volumen testicular de $4 \mathrm{~cm}^{3}$ o mayor).

- Intervención: cualquier intervención diferente de los aGnRH con o sin cointervenciones. Se incluyen intervenciones psicosociales, hormona de crecimiento o cualquier otra intervención que tuviera como finalidad impactar en alguno de los desenlaces de interés.

- Control: sujetos que no recibieron la intervención. Pueden ser sujetos que no recibieron ninguna intervención 0 que recibieron una intervención alternativa.

- Desenlaces: talla adulta o casi adulta, medidas de impacto psicológico o de calidad de vida, medidas de éxito en el bloqueo de la pubertad, medidas de salud ósea y medidas de salud metabólica.

\section{ESTRATEGIA DE BÚSQUEDA}

Se realizó una búsqueda en PubMed con los términos ("precocious puberty") AND ("treatment" OR "therapy") NOT ("GnRH analog" OR "GnRH agonist" OR "gonadotropin releasing hormone agonist" OR "gonadotropin releasing hormone analog" OR "gonadotropin-releasing hormone agonist" OR "gonadotropin-releasing hormone analog"). Filtro: ensayos clínicos.

También se incluyeron los estudios identificados en la búsqueda de la revisión sistemática «Análogos de la GnRH para el tratamiento de la pubertad precoz» (sección anterior de este documento).

\section{Selección de ESTUdios}

Todos los títulos y los resúmenes identificados en la búsqueda fueron evaluados por dos revisores, quienes examinaron el texto completo de todos los ensayos que potencialmente cumplían los criterios de inclusión. Se resolvieron los desacuerdos mediante discusión con un tercer revisor hasta llegar a un consenso.

\section{EXTRACCIÓN DE DATOS}

Dos revisores por estudio extrajeron los datos relevantes de los estudios en un formato diseñado previamente. Cuando hubo discordancia en la captura de datos se discutió con un tercer revisor hasta llegar a un consenso.

\section{Evaluación de CALIDAD DE LOS ESTUdIOS INCLUIDOS}

Se evaluó el riesgo de sesgo mediante la herramienta CASPe para ensayos clínicos ${ }^{1}$. Una vez considerados los rubros evaluados por este instrumento, los miembros del grupo desarrollador de la guía asignaron niveles para la calidad (de menor a mayor):,$-+y++$.

\section{Resultados}

Se identificaron 140 referencias. Entre estas y las identificadas en la búsqueda para la revisión «Análogos de la GnRH para el tratamiento de la pubertad precoz", nueve estudios cumplieron los criterios de inclusión: cuatro que evaluaron el efecto de la cointervención con hormona del crecimiento en la talla final (Tabla 5 del anexo), uno que evaluó la cointervención con calcio para la densidad mineral ósea, uno que evaluó la cointervención con un inhibidor de la aromatasa, uno que evaluó la cointervención con vitamina $\mathrm{A}$ y con hierro, y otro que evaluó la cointervención con un antagonista de la GnRH. También se encontró un estudio comparativo que evaluó el uso de medroxiprogesterona (Tabla 6 del anexo). De los estudios con hormona del crecimiento solo se evaluaron los ensayos clínicos cuyo desenlace 
fuera la talla final, y no otra medida subrogada de crecimiento.

\section{Revisión sistemática de estudios de pruebas diagnósticas para la pubertad precoz}

\section{Metodología}

\section{Criterios de inclusión}

- Tipo de estudios: estudios de exactitud de pruebas diagnósticas para la pubertad de origen central.

- Tipo de participantes: niñas menores de 8 años con crecimiento mamario (estadio Tanner II o mayor) y niños menores de 9 años con crecimiento testicular (volumen testicular de $4 \mathrm{~cm}^{3}$ o mayor).

- Prueba índice: cualquier prueba con el propósito de diagnosticar la pubertad de origen central. Se incluyeron mediciones basales de hormonas, pruebas de estimulación con gonadotropinas 0 análogos de gonadotropinas, y mediciones ultrasonográficas.

- Pruebas de referencia (gold standard): las pruebas que se consideraron válidas como estándar fueron la progresión de la pubertad en un periodo de 6 meses (si es que esta fue definida de forma clara y precisa) y unos valores de hormona luteinizante $(\mathrm{LH})>5 \mathrm{U} / \mathrm{l}$ después de un estímulo con $\mathrm{GnRH}$ por vía intravenosa o con un aGnRH por vía subcutánea.

\section{ESTRATEGIA DE BÚSQUEDA}

La búsqueda se realizó en PubMed con los términos ("precocious puberty" [Title/Abstract] OR "early puberty" [Title/Abstract]) AND (Diagnosis [Title/ Abstract] OR diagnostic [Title/Abstract] OR sensitivity [Title/Abstract] OR specificity [Title/Abstract] OR "predictive value" [Title/Abstract] OR "false positive" [Title/ Abstract] OR "false negative" [Title/Abstract] OR "differential diagnosis" [Title/abstract] OR "secondary causes" [Title/abstract]).

\section{Selección de ESTUdios}

Todos los títulos y los resúmenes identificados en la búsqueda fueron evaluados por dos revisores, quienes examinaron el texto completo de todos los ensayos que potencialmente cumplían los criterios de inclusión. Se resolvieron los desacuerdos mediante discusión con un tercer revisor hasta que se llegó a un consenso.

\section{EXTRACCIÓN DE DATOS}

Dos revisores extrajeron los datos relevantes de cada estudio seleccionado en un formato previamente diseñado de forma independiente. Cuando hubo discordancia en la captura de datos se discutió con un tercer revisor hasta llegar a un consenso.

\section{EVALUACIÓN DE LA CALIDAD DE LOS ESTUDIOS INCLUIDOS}

Los estudios se clasificaron en tres niveles: los de nivel 1 son los de mayor calidad, los de nivel 2 solo presentan uno de los criterios de sesgo evaluados y los de nivel 3 son aquellos con dos o más criterios de sesgo.

\section{Resultados}

Se identificaron 668 referencias en PubMed hasta el 13 de febrero de 2018, de las que se excluyeron 644 por no cumplir los criterios de inclusión. Se extrajeron los datos de 24 estudios. Algunos estudios evaluaron más de una prueba diagnóstica:

- Valores únicos de gonadotropinas u hormonas sexuales vs. prueba de estimulación con $\mathrm{GnRH}$ : 17 estudios (Tabla 7 del anexo).

- Prueba de estimulación con GnRH vs. evolución: 12 estudios (Tabla 8 del anexo).

- Ultrasonido: ocho estudios (Tabla 9 del anexo).

- Datos clínicos: cuatro estudios (Tabla 10 del anexo).

- Inhibina y hormona antimulleriana: dos estudios (Tabla 11 del anexo).

- LH matutina: dos estudios (Tabla 12 del anexo).

- Otras pruebas: dos estudios (Tabla 13 del anexo).

\section{Anexo}

Las tablas del anexo pueden consultarse en: www.doi.org/10.24875/BMHIM.20000087.

\section{Bibliografía}

1. Cabello JB. Plantilla para ayudarte a entender un ensayo clínico. En: CASPe, editor. Guías CASPe de lectura crítica de la literatura médica. Cuaderno 1. Alicante: CASPe; 2005. p. 5-8.

2. Cassio A, Cacciari E, Balsamo A, Bal M, Tassinari D. Randomised trial of $\mathrm{LHRH}$ analogue treatment on final height in girls with onset of puberty aged 7.5-8.5 years. Arch Dis Child. 1999;81:329-32.

3. Kauli R, Galatzer A, Kornreich L, Lazar L, Pertzelan A, Laron Z. Final height of girls with central precocious puberty, untreated versus treated with cyproterone acetate or $\mathrm{GnRH}$ analogue. A comparative study with re-evaluation of predictions by the Bayley-Pinneau method. Horm Res. 1997;47:54-61.

4. Savaş-Erdeve S, Şıklar Z, Hacıhamdioğlu B, Kocaay P, Camtosun E Öcal G, et al. Gonadotropin-releasing hormone analogue treatment in females with moderately early puberty: no effect on final height. J Clin Res Pediatr Endocrinol. 2016;8:211-7. 
5. Lazar L, Kauli R, Pertzelan A, Phillip M. Gonadotropin-suppressive therapy in girls with early and fast puberty affects the pace of puberty but not total pubertal growth or final height. J Clin Endocrinol Metab. 2002;87:2090-4

6. Fuld K, Chi C, Neely EK. A randomized trial of 1- and 3-month depot leuprolide doses in the treatment of central precocious puberty. J Pediatr. 2011;159:982-7.e1.

7. Lee PA, Klein K, Mauras N, Neely KE, Bloch CA, Larsen L, et al. Efficacy and safety of leuprolide acetate 3-month depot 11.25 milligrams or 30 milligrams for the treatment of central precocious puberty. J Clin Endocrinol Metab. 2012:97:1572-80.

8. Mericq V, Lammoglia JJ, Unanue N, Villaroel C, Hernández MI, Ávila A et al. Comparison of three doses of leuprolide acetate in the treatment of central precocious puberty: preliminary results. Clin Endocrinol. 2009;71:686-90.

9. Mostafa NM, Hosmane B, Larsen LM, Chwalisz K, Chiu YL, Pradhan RS. Pharmacokinetic and exposure-response analyses of leuprolide following administration of leuprolide acetate 3-month depot formulations to children with central precocious puberty. Clin Drug Investig. 2014;34:441-8.

10. Lazar L, Lebenthal Y, Yackobovitch-Gavan M, Shalitin S, De Vries L, Phillip M, et al. Treated and untreated women with idiopathic precocious puberty: BMI evolution, metabolic outcome, and general health between third and fifth decades. J Clin Endocrinol Metab. 2015;100:1445-51.

11. Lazar L, Meyerovitch J, De Vries L, Phillip M, Lebenthal Y. Treated and untreated women with idiopathic precocious puberty: long-term follow-up and reproductive outcome between the third and fifth decades. Clin Endocrinol. 2014;80:570-6

12. Alessandri SB, Pereira FA, Villela RA, Antonini SRR, Elias PCL, Martinelli $\mathrm{Jr} \mathrm{CE}$, et al. Bone mineral density and body composition in girls with idiopathic central precocious puberty before and after treatment with a gonadotropin-releasing hormone agonist. Clinics. 2012;67:591-6.

13. Chiocca E, Dati E, Baroncelli GI, Mora S, Parrini D, Erba P, et al. Body mass index and body composition in adolescents treated with gonadotropin-releasing hormone analogue triptorelin depot for central precocious puberty: data at near final height. Neuroendocrinology. 2009;89:441-7.

14. Pasquino AM, Pucarelli I, Accardo F, Demiraj V, Segni M, Di Nardo R Long-term observation of 87 girls with idiopathic central precocious puberty treated with gonadotropin-releasing hormone analogs: impact on adult height, body mass index, bone mineral content, and reproductive function. J Clin Endocrinol Metab. 2008;93:190-5.

15. Xhrouet-Heinrichs D, Lagrou K, Heinrichs C, Craen M, Dooms L, Malvaux $\mathrm{P}$, et al. Longitudinal study of behavioral and affective patterns in girls with central precocious puberty during long-acting triptorelin therapy. Acta Paediatr. 2008;86:808-15.

16. Kelly $Y$, Zilanawala A, Sacker A, Hiatt R, Viner R. Early puberty in 11-year-old girls: Millennium Cohort Study findings. Arch Dis Child. 2017;102:232-7.

17. Lee PA, Luce M, Bacher P. Monitoring treatment of central precocious puberty using basal luteinizing hormone levels and practical considerations for dosing with a 3-month leuprolide acetate formulation. J Pediatr Endocrinol Metab. 2016;29:1249-57.

18. Mensah FK, Bayer JK, Wake M, Carlin JB, Allen NB, Patton GC. Early puberty and childhood social and behavioral adjustment. J Adolesc Health. $2013 ; 53: 118-24$

19. Copeland W, Shanahan L, Miller S, Costello EJ, Angold A, Maughan B. Outcomes of early pubertal timing in young women: a prospective population-based study. Am J Psychiatr. 2010;167:1218-25.

20. Michaud PA, Suris JC, Deppen A. Gender-related psychological and behavioural correlates of pubertal timing in a national sample of Swiss adolescents. Mol Cell Endocrinol. 2006;254-255:172-8.

21. Johansson TS, Ritzén EM. Very long-term follow-up of girls with early and late menarche. Abnormalities in puberty. Endocr Dev. 2005;8:126-36.

22. Baumann DA, Landolt MA, Wetterwald R, Dubuis JM, Sizonenko PC Werder EA. Psychological evaluation of young women after medical treatment for central precocious puberty. Horm Res. 2001;56:45-50.

23. Schoevaart CE, Drop SL, Otten BJ, Slijper FM, Degenhart HJ. Growth analysis up to final height and psychosocial adjustment of treated and untreated patients with precocious puberty. Horm Res. 1990;34:197-203.

24. Jackson PL, Ott MJ. Perceived self-esteem among children diagnosed with precocious puberty. J Pediatr Nurs. 1990:5:190-203.

25. Nacinovich R, Buzi F, Oggiano S, Rossi S, Spada S, Broggi F, et al. Body experiences and psychopathology in idiopathic central precocious and early puberty. Minerva Pediatr. 2016:68:11-8.

26. Schoelwer MJ, Donahue KL, Didrick P, Eugster EA. One-year follow-up of girls with precocious puberty and their mothers: do psychological assessments change over time or with treatment? Horm Res Paediatr. 2017:88:347-53.

27. Mul D, Oostdijk W, Waelkens JJ, Schulpen TW, Drop SL. Gonadotrophin releasing hormone agonist treatment with or without recombinant human $\mathrm{GH}$ in adopted children with early puberty. Clin Endocrinol (Oxf). 2001:55:121-9.

28. Mul D, Oostdijk W, Waelkens JJ, Drop SL. Final height after treatment of early puberty in short adopted girls with gonadotrophin releasing hor- mone agonist with or without growth hormone. Clin Endocrinol (Oxf). 2005;63:185-90

29. Pasquino AM, Pucarelli I, Segni M, Matrunola M, Cerroni F, Cerrone F. Adult height in girls with central precocious puberty treated with gonadotropin-releasing hormone analogues and growth hormone. J Clin Endocrinol Metab. 1999;84:449-52.

30. Pucarelli I, Segni M, Ortore M, Arcadi E, Pasquino AM. Effects of combined gonadotropin-releasing hormone agonist and growth hormone therapy on adult height in precocious puberty: a further contribution. J Pediatr Endocrinol Metabol. 2003;16:1005-10.

31. Tuvemo T, Jonsson B, Gustafsson J, Albertsson-Wikland K, Aronson AS, Häger $A$, et al. Final height after combined growth hormone and $\mathrm{GnRH}$ analogue treatment in adopted girls with early puberty. Acta Paediatr. 2004;93:1456-62.

32. Antoniazzi F, Zamboni G, Bertoldo F, Lauriola S, Mengarda F, PietrobeIli $A$, et al. Bone mass at final height in precocious puberty after gonadotropin-releasing hormone agonist with and without calcium supplementation. J Clin Endocrinol Metabol. 2003:88:1096-101.

33. Abodovsky N, Matus de la Parra A, Vivanco X, Onetto E. [Treatment of true precocious puberty with medroxyprogesterone acetate]. Bol Med Hosp Infant Mex. 1979;36:581-97.

34. Karamizadeh Z, Mohammadi H. 661 Vitamin A and iron as an adjuvant therapy in addition of $\mathrm{GnRH}$ agonist in precocious puberty. Arch Dis Child. 2012;97(Suppl 2):A191.

35. Papadimitriou DT, Dermitzaki E, Papagianni M, Papaioannou G, Papaevangelou V, Papadimitriou A. Anastrozole plus leuprorelin in early maturing girls with compromised growth: the "GAIL" study. J Endocrinol Invest. 2016:39:439-46

36. Roth CL, Brendel L, Rückert C, Hartmann K. Antagonistic and agonistic $\mathrm{GnRH}$ analogue treatment of precocious puberty: tracking gonadotropin concentrations in urine. Horm Res. 2005;63:257-62.

37. Binay $\mathrm{C}$, Simsek $\mathrm{E}, \mathrm{Bal} \mathrm{C}$. The correlation between $\mathrm{GnRH}$ stimulation testing and obstetric ultrasonographic parameters in precocious puberty. J Pediatr Endocrinol Metab. 2014;27:1193-9.

38. Brito VN, Batista MC, Borges MF, Latronico AC, Kohek MBF, Thirone $A C P$, et al. Diagnostic value of fluorometric assays in the evaluation of precocious puberty. J Clin Endocrinol Metab. 1999;84:3539-44.

39. Brito VN, Latronico AC, Arnhold IJP, Mendonca BB. A single luteinizing hormone determination 2 hours after depot leuprolide is useful for therapy monitoring of gonadotropin-dependent precocious puberty in girls. $J$ Clin Endocrinol Metab. 2004;89:4338-42.

40. Cavallo A, Richards GE, Busey S, Michaels SE. A simplified gonadotrophin-releasing hormone test for precocious puberty. Clin Endocrinol. 1995;42:641-6.

41. Choi JH, Shin YL, Yoo HW. Predictive factors for organic central precocious puberty and utility of simplified gonadotropin-releasing hormone tests. Pediatr Int. 2007;49:806-10.

42. De Filippo G, Rendina D, Nazzaro A, Lonardo F, Bouvattier C, Strazzullo $P$. Baseline inhibin $B$ levels for diagnosis of central precocious puberty in girls. Horm Res Paediatr. 2013;80:207-12.

43. Freire AV, Escobar ME, Gryngarten MG, Arcari AJ, Ballerini MG, Bergadá I, et al. High diagnostic accuracy of subcutaneous triptorelin test compared with $\mathrm{GnRH}$ test for diagnosing central precocious puberty in girls. Clin Endocrinol (Oxf). 2013;78:398-404.

44. Haber HR, Wollmann HA, Ranke MB. Pelvic ultrasonography: early differentiation between isolated premature thelarche and central precocious puberty. Eur J Pediatr. 1995;154:182-6.

45. Kandemir N, Demirbilek H, Özön ZA, Gönç N, Alikaşifoğlu A. GnRH stimulation test in precocious puberty: single sample is adequate for diagnosis and dose adjustment. J Clin Res Pediatr Endocrinol. 2011; 3:12-7

46. Kim HK, Kee SJ, Seo JY, Yang EM, Chae HJ, Kim CJ. Gonadotropin-releasing hormone stimulation test for precocious puberty. Korean J Lab Med. 2011;31:244-9.

47. Lee HS, Park HK, Ko JH, Kim YJ, Hwang JS. Utility of basal luteinizing hormone levels for detecting central precocious puberty in girls. Horm Metab Res. 2012;44:851-4

48. Neely EK, Wilson DM, Lee PA, Stene M, Hintz RL. Spontaneous serum gonadotropin concentrations in the evaluation of precocious puberty. $\mathrm{J}$ Pediatr. 1995;127:47-52.

49. Pasternak Y, Friger M, Loewenthal N, Haim A, Hershkovitz E. The utility of basal serum LH in prediction of central precocious puberty in girls. Eur J Endocrinol. 2012;166:295-9.

50. Supornsilchai V, Wacharasindhu S, Aroonparkmongkol S, Hiranrat P, Srivuthana S. Basal luteinizing hormone/follicle stimulating hormone ratio in diagnosis of central precocious puberty. J Med Assoc Thai. 2003;86(Suppl 2):S145-51.

51. Wacharasindhu S, Srivuthana S, Aroonparkmongkol S, Shotelersuk V. A cost-benefit of $\mathrm{GnRH}$ stimulation test in diagnosis of central precocious puberty (CPP). J Med Assoc Thai. 2000:83:1105-11.

52. Calcaterra V, Sampaolo P, Klersy C, Larizza D, Alfei A, Brizzi V, et al. Utility of breast ultrasonography in the diagnostic work-up of precocious puberty and proposal of a prognostic index for identifying girls with ra- 
Bol Med Hosp Infant Mex. 2020;77(Supl 1)

pidly progressive central precocious puberty. Ultrasound Obstet Gynecol. 2009;33:85-91

53. Carretto F, Salinas-Vert I, Granada-Yvern ML, Murillo-Vallés M, Gómez-Gómez C, Puig-Domingo $M$, et al. The usefulness of the leuprolide stimulation test as a diagnostic method of idiopathic central precocious puberty in girls. Horm Metab Res. 2014;46:959-63.

54. Chen $T$, Wu H, Xie R, Wang F, Chen X, Sun H, et al. Serum anti-müllerian hormone and inhibin $\mathrm{B}$ as potential markers for progressive centra precocious puberty in girls. J Pediatr Adolesc Gynecol. 2017;30:362-6.

55. Chin VL, Cai Z, Lam L, Shah B, Zhou P. Evaluation of puberty by verifying spontaneous and stimulated gonadotropin values in girls. J Pediatr Endocrinol Metab. 2015;28:387-92

56. de Vries L, Horev G, Schwartz M, Phillip M. Ultrasonographic and clinical parameters for early differentiation between precocious puberty and premature thelarche. Eur J Endocrinol. 2006;154:891-8.

57. Harrington J, Palmert MR, Hamilton J. Use of local data to enhance uptake of published recommendations: an example from the diagnostic evaluation of precocious puberty. Arch Dis Child. 2014:99:15-20.

58. Junqueira FR, Lara LA, Martins WP, Ferriani RA, Rosa-E-Silva AC, de Sá MF, et al. Gonadotropin and estradiol levels after leuprolide stimulation tests in Brazilian girls with precocious puberty. J Pediatr Adolesc Gynecol. 2015;28:313-6.

59. Poomthavorn $P$, Khlairit $P$, Mahachoklertwattana $P$. Subcutaneous gonadotropin-releasing hormone agonist (triptorelin) test for diagnosing precocious puberty. Horm Res. 2009;72:114-9.
60. Sathasivam A, Garibaldi L, Shapiro S, Godbold J, Rapaport R. Leuprolide stimulation testing for the evaluation of early female sexual maturation. Clin Endocrinol. 2010;73:375-81.

61. Zung A, Burundukov E, Ulman M, Glaser T, Rosenberg M, Chen M, et al. The diagnostic value of first-voided urinary LH compared with GNRH-stimulated gonadotropins in differentiating slowly progressive from rapidly progressive precocious puberty in girls. Eur J Endocrinol. 2014;170:749-58.

62. Badouraki M, Christoforidis A, Economou I, Dimitriadis AS, Katzos G. Evaluation of pelvic ultrasonography in the diagnosis and differentiation of various forms of sexual precocity in girls. Ultrasound Obstet Gynecol. 2008;32:819-27.

63. Battaglia C, Regnani G Mancini F lughetti L Venturoli S, Flamigni C Pelvic sonography and uterine artery color Doppler analysis in the diagnosis of female precocious puberty. Ultrasound Obstet Gynecol. 2002;19:386-91.

64. Battaglia C, Mancini F, Regnani G, Persico N, lughetti L, De Aloysio D. Pelvic ultrasound and color Doppler findings in different isosexual precocities. Ultrasound Obstet Gynecol. 2003;22:277-83.

65. Eksioglu AS, Yilmaz S, Cetinkaya S, Cinar G, Yildiz YT, Aycan Z. Value of pelvic sonography in the diagnosis of various forms of precocious puberty in girls. J Clin Ultrasound. 2013;41:84-93.

66. Zhu SY, Du ML, Huang TT. An analysis of predictive factors for the conversion from premature thelarche into complete central precocious puberty. J Pediatr Endocrinol Metab. 2008;21:533-8.

67. Kolby N, Busch AS, Aksglaede L, Sørensen K, Petersen JH, Andersson AM, et al. Nocturnal urinary excretion of FSH and $\mathrm{LH}$ in children and adolescents with normal and early puberty. J Clin Endocrinol Metab. 2017;102:3830-8. 


\section{Síntesis de la evidencia (tablas): Guía de práctica clínica para el diagnóstico y el tratamiento de la pubertad precoz}

M. Fernanda Castilla-Peón ${ }^{1 *}$, Margarita Torres-Tamayo ${ }^{2}$, Jessie N. Zurita-Cruz ${ }^{3}$, Blanca E. Aguilar-Herrera4 ${ }^{4}$ América L. Miranda-Lora ${ }^{1}$, Aleida J. Rivera-Hernández ${ }^{4}$, Raúl Calzada-León ${ }^{5}$ Marco A. Morales-Pérez ${ }^{6}$, Miriam M. Padrón-Martínez ${ }^{5}$, María L. Ruiz-Reyes ${ }^{5}$, Leticia M. García-Morales ${ }^{1}$, Consuelo Barrón-Uribe ${ }^{3}$, Sletza L. Arguinzoniz-Valenzuela ${ }^{5}$, Mayra C. Torres-Castañeda ${ }^{7}$ Lorena Lizárraga-Paulin ${ }^{7}$ Jorge A. Núñez-Hernández ${ }^{8,9}$, Judith Cornejo-Barrera ${ }^{10}$, María T. Vidal-González ${ }^{11}$, María R. Martínez-Alvarado², Elisa Nishimura-Meguro ${ }^{3}$, Luz E. Bravo-Ríos ${ }^{3}$, Eulalia P. Garrido-Magaña ${ }^{4}$, José A. Orozco-Morales ${ }^{1}$, Patricia G. Medina-Bravo y Ninel Coyote-Estrada ${ }^{3}$

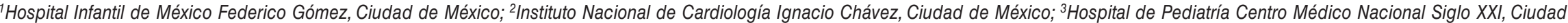
de México; ${ }^{4}$ Sociedad Mexicana de Endocrinología Pediátrica, Ciudad de México; 5 Instituto Nacional de Pediatría, Ciudad de México; ${ }^{6} \mathrm{Hospital}$ General de Zona No. 18, Playa del Carmen, Quintana Roo; ${ }^{7}$ Hospital General del Centro Médico Nacional La Raza, Ciudad de México; ${ }^{8}$ Hospital General Regional 220, Instituto Mexicano del Seguro Social, Estado de México; ${ }^{9}$ nstituto Materno Infantil del Estado de México, Toluca, Estado de México; ${ }^{10} \mathrm{Hospital}$ Infantil de Tamaulipas, Ciudad Victoria, Tamaulipas; ${ }^{11}$ Hospital del Niño y el Adolescente Morelense, Cuernavaca, Morelos. México

Tablas correspondientes al documento de Síntesis de la evidencia: Guía de práctica clínica para el diagnóstico y el tratamiento de la pubertad precoz. Tabla 1. Efecto de los aGnRH para el tratamiento de la pubertad precoz en la talla adulta

\begin{tabular}{|c|c|c|c|c|c|c|c|c|c|c|c|c|c|}
\hline \multirow[t]{2}{*}{ Autores (año) } & \multirow[t]{2}{*}{$\begin{array}{l}\text { Sexo y edad de } \\
\text { inicio de pubertad }\end{array}$} & \multirow[t]{2}{*}{$\begin{array}{l}\text { Manifestaciones clínicas al } \\
\text { inicio }\end{array}$} & \multirow[t]{2}{*}{ Diseño de estudio } & \multirow[t]{2}{*}{$\begin{array}{l}\text { Grupo } 1 \\
\text { (experimental) }\end{array}$} & \multirow[t]{2}{*}{$\begin{array}{l}\text { Grupo } 2 \\
\text { (comparativo) }\end{array}$} & \multicolumn{3}{|c|}{$\begin{array}{l}\text { Talla adulta } \\
\text { grupo } 1(\mathrm{~cm})\end{array}$} & \multicolumn{3}{|c|}{$\begin{array}{l}\text { Talla adulta } \\
\text { grupo } 2(\mathrm{~cm})\end{array}$} & \multirow[t]{2}{*}{$\begin{array}{l}\text { Otros } \\
\text { desenlaces }\end{array}$} & \multirow[t]{2}{*}{ Calidad } \\
\hline & & & & & & $\mathbf{N}$ & Media & DE & $\mathbf{N}$ & Media & DE & & \\
\hline $\begin{array}{l}\text { Cassio, } \\
\text { et al. }(1999)^{2}\end{array}$ & $\begin{array}{l}F \\
7.5-8.5 \text { años }\end{array}$ & $\begin{array}{l}\text { Desarrollo mamario entre los } \\
7.5 \text { y } 8.5 \text { años, EO adelantada } \\
\text { y zVC } \geq 1.5 \text {, sin deficiencia } \\
\text { de GH, sin HSC, sin } \\
\text { enfermedades neurológicas, } \\
\text { con RM de cráneo y USG } \\
\text { pélvico normal }\end{array}$ & $\begin{array}{l}\text { ECCA } \\
\text { La intervención se } \\
\text { asignó } \\
\text { "alternativamente» }\end{array}$ & $\begin{array}{l}\text { Triptorelina } 3.75 \\
\mathrm{mg} \text { IM c/4 } \\
\text { semanas por } 25 \\
\text { meses (12-40 } \\
\text { meses) }\end{array}$ & Sin tratamiento & 20 & 152.7 & 7.2 & 18 & 152.5 & 5.7 & $\begin{array}{l}\text { Talla en } \\
\text { menarca } \\
\text { Crecimiento } \\
\text { posmenarca } \\
\text { Diferencia } \\
\text { TBF-TA }\end{array}$ & $(+)$ \\
\hline \multirow[t]{3}{*}{$\begin{array}{l}\text { Kauli, et al. } \\
(1997)^{3}\end{array}$} & \multirow[t]{3}{*}{$\begin{array}{l}F \\
8.3 \pm 1.5 \text { años } \\
(3.5-10.9)\end{array}$} & \multirow{3}{*}{$\begin{array}{l}\text { PPC idiopática (signos antes de } \\
\text { los } 8 \text { años, curso progresivo, } \\
\text { aumento de VC y EO) } \\
\text { Exclusión: RCIU y otras } \\
\text { condiciones que afecten la } \\
\text { talla } \\
\text { Rechazaron tratamiento } \\
28 / 102 \\
\text { Edad de inicio de las } \\
\text { manifestaciones } \\
\text { Grupo 1: } 6.2 \pm 1.5 \text { años } \\
\text { (1.2-7.5) } \\
\text { Grupo 2: } 6.6 \pm 1 \text { año (2-7.7) } \\
\text { Edad de primera valoración } \\
\text { Grupo 1: } 7.4 \pm 1.7 \text { años } \\
\text { (3-10.6) } \\
\text { Grupo 2: } 7.8 \pm 1 \text { año (6.5-9.7) }\end{array}$} & \multirow{3}{*}{$\begin{array}{l}\text { EC no aleatorizado } \\
\text { Incluye un grupo que } \\
\text { no aceptó } \\
\text { tratamiento. Estos } \\
\text { individuos se } \\
\text { analizaron en dos } \\
\text { subgrupos de } \\
\text { acuerdo con el buen } \\
\text { o mal pronóstico de } \\
\text { talla final }\end{array}$} & $\begin{array}{l}\text { Triptorelina } 1.5-3 \\
\mu \mathrm{g} / \mathrm{kg} / \text { día SC } 0 \\
\text { triptorelina } 3 \mathrm{mg} \\
\text { IM c/4 semanas } \\
\text { por } 3.2 \pm 1.3 \\
\text { años }(2-7.5)\end{array}$ & $\begin{array}{l}\text { Ciproterona } \\
70-100 \mathrm{mg} / \mathrm{m}^{2} / \mathrm{día} \\
\text { por } 3.6 \pm 1.6 \\
\text { años }(2-7.7)\end{array}$ & 48 & 159.6 & 6.3 & 26 & 157.8 & 5.1 & $\begin{array}{l}\text { TA-Talla } \\
\text { predicha } \\
\text { TA-TBF (datos } \\
\text { no } \\
\text { desagregados } \\
\text { por edad) }\end{array}$ & $(+)$ \\
\hline & & & & Ciproterona & $\begin{array}{l}\text { Sin tratamiento } \\
\text { por elección }\end{array}$ & 26 & 157.8 & 5.1 & 28 & 155.5 & 7.5 & & \\
\hline & & & & $\begin{array}{l}\text { Triptorelina SC o } \\
\text { triptorelina }\end{array}$ & $\begin{array}{l}\text { Sin tratamiento } \\
\text { por elección }\end{array}$ & 48 & 159.6 & 6.3 & 28 & 155.5 & 7.5 & & \\
\hline \multirow[t]{2}{*}{$\begin{array}{l}\text { Savaş-Erdeve, } \\
\text { et al. }(2016)^{4}\end{array}$} & $\begin{array}{l}F \\
8.7 \pm 0.8 \text { al inicio } \\
\text { del tratamiento } \\
\text { E0 de grupo } \\
\text { tratado } \\
<10.5 \text { años }\end{array}$ & \multirow[t]{2}{*}{$\begin{array}{l}\text { Pubertad temprana: Tanner } \\
\text { mamario } \geq \text { II a los } 7-8.5 \text { años } \\
\text { Descartadas causas } \\
\text { secundarias }\end{array}$} & $\begin{array}{l}\text { EC no aleatorizado } \\
\text { Grupo control } \\
\text { rechazaron el } \\
\text { tratamiento } \\
\text { Grupo de tratamiento } \\
\text { con menos edad, } \\
\text { menos talla, más } \\
\text { adelanto puberal que } \\
\text { el grupo control } \\
\text { (Tanner III vs II). } \\
\text { Talla blanco y } \\
\text { pronóstico de talla } \\
\text { similar }\end{array}$ & $\begin{array}{l}\text { Leuprorelina } \\
3.75 \mathrm{mg} / 28 \text { días }\end{array}$ & $\begin{array}{l}\text { Ninguno por } \\
\text { elección }\end{array}$ & 18 & 159 & 4.3 & 8 & 158.3 & 5.6 & & $(-)$ \\
\hline & $\begin{array}{l}\text { E0 del grupo } \\
\text { tratado }>10.5 \\
\text { años }\end{array}$ & & $\begin{array}{l}\text { Grupo tratado más } \\
\text { adelantado que } \\
\text { control (Tanner IV vs } \\
\text { II), menor predicción } \\
\text { de talla final, mayor } \\
\text { EO }\end{array}$ & $\begin{array}{l}\text { Leuprorelina } \\
3.75 \mathrm{mg} / 28 \text { días }\end{array}$ & $\begin{array}{l}\text { Ninguno por } \\
\text { elección }\end{array}$ & 23 & 160 & 5.5 & 8 & 158.3 & 5.6 & $\begin{array}{l}\text { Descriptivos de } \\
\text { antecedentes y } \\
\text { características } \\
\text { generales } \\
\text { Delta EO y otros } \\
\text { subrogados }\end{array}$ & \\
\hline $\begin{array}{l}\text { Lazar, et al. } \\
(2002)^{5}\end{array}$ & $\begin{array}{l}\text { F } \\
\text { Pubertad } \\
\text { temprana/ } \\
\text { rápidamente } \\
\text { progresiva (8-9 } \\
\text { años) }\end{array}$ & $\begin{array}{l}\text { Transición de Tanner II a III } \\
\text { en menos de } 1.3 \text { años, } \\
\text { aceleración EO, LH } \\
\text { estimulada }<7 \text { UI/I, USG } \\
\text { pélvico puberal. } \\
\text { Exclusión: prematuridad, } \\
\text { PEG, enfermedades crónicas, } \\
\text { displasias, enfermedades del } \\
\text { SNC, HSC, radioterapia, } \\
\text { quimioterapia }\end{array}$ & $\begin{array}{l}\text { No aleatorizado } \\
\text { Comparación entre } \\
\text { el grupo que aceptó } \\
\text { vs. el grupo que no } \\
\text { aceptó tratamiento }\end{array}$ & $\begin{array}{l}\text { Triptorelina } \\
3.75 \mathrm{mg} / \mathrm{mes} \\
\text { hasta } 11- \\
12 \text { años, } \\
\text { EO } 12-12.5 \text { años, } \\
\text { VC } 4 \mathrm{~cm} / \text { años } \\
\text { por } 2-4 \text { años }\end{array}$ & Ninguno & 63 & 157.3 & 6.2 & 63 & 156.66 & 5.7 & IMC final & $(+)$ \\
\hline
\end{tabular}

aGnRH: agonistas de la hormona liberadora de gonadotropinas; DE: desviación estándar; EC: ensayo clínico; ECCA: ensayo clínico controlado aleatorizado; EO: edad ósea; F: femenino; GH: hormona de crecimiento; HSC: hiperplasia suprarrenal

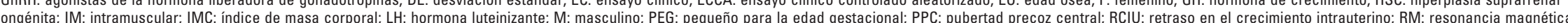
congenita; IM: intramuscular; IMC: indice de masa corporal; LA: hormona luteinizante; M: masculino; PEG: pequeño para la edad gestacional; PPC: puber:
de cráneo; SC: subcutáneo; SNC: sistema nervioso central; TA: talla adulta; TBF: talla blanco familiar; USG: ultrasonografía; VC: velocidad de crecimiento. 
Bol Med Hosp Infant Mex. 2020;77Supl(1)

Tabla 2. Tratamiento con aGnRH y porcentaje de éxito en la supresión de la pubertad

\begin{tabular}{|c|c|c|c|c|c|c|c|c|c|c|c|c|}
\hline Autores (año) & $\begin{array}{l}\text { Sexo y edad al } \\
\text { inicio del } \\
\text { tratamiento }\end{array}$ & $\begin{array}{l}\text { Manifestaciones clínicas } \\
\text { al inicio }\end{array}$ & $\begin{array}{l}\text { Criterio } \\
\text { diagnóstico } \\
\text { de falla de } \\
\text { supresión }\end{array}$ & $\begin{array}{l}\text { Diseño del } \\
\text { estudio }\end{array}$ & $\begin{array}{l}\text { Grupo } 1 \\
\text { (experimental) }\end{array}$ & $\begin{array}{l}\text { Grupo } 2 \\
\text { (comparativo) }\end{array}$ & $\mathbf{N}$ & $\begin{array}{c}\text { Porcentaje } \\
\text { de éxito } \\
\text { grupo } 1\end{array}$ & $\mathbf{N}$ & $\begin{array}{c}\text { Porcentaje } \\
\text { de éxito } \\
\text { grupo } 2\end{array}$ & $\begin{array}{l}\text { Otros } \\
\text { desenlaces }\end{array}$ & Calidad \\
\hline \multirow[t]{2}{*}{$\begin{array}{l}\text { Fuld, et al. } \\
(2011)^{6}\end{array}$} & \multirow[t]{2}{*}{$\begin{array}{l}8.1 \pm 1.9 \text { años } \\
\text { Niños }(n=5) \\
\text { Niñas }(n=49)\end{array}$} & \multirow{2}{*}{$\begin{array}{l}\text { PP en niñas }<8 \text { años y en } \\
\text { niños }<9 \text { años } \\
\text { LH basal }>0.3 \mathrm{UI} / \mathrm{I} \text { o } \\
\text { estimulada }>5 \mathrm{UI} / \mathrm{I} \text {. Se } \\
\text { incluyeron cuatro de } \\
\text { mayor edad } \\
\text { Se eliminaron los que } \\
\text { tuvieron LH estimulada } \\
>6 \mathrm{UI} / \mathrm{l} \text { en dos visitas }\end{array}$} & \multirow[t]{2}{*}{$\begin{array}{l}\text { LH estimulada } \\
>4 \mathrm{UI} / \mathrm{l}\end{array}$} & \multirow[t]{2}{*}{$\begin{array}{l}\text { ECCA } \\
\text { Mezcla } \\
\text { confusa de } \\
\text { grupos }\end{array}$} & $\begin{array}{l}\text { Leuprorelina } \\
\text { depósito } \\
7.5 \mathrm{mg} / \mathrm{mes}\end{array}$ & $\begin{array}{l}\text { Leuprorelina } \\
\text { depósito } \\
11.25 \mathrm{mg} / 3 \\
\text { meses }\end{array}$ & 18 & 94 & 21 & 67 & \multirow[t]{2}{*}{$\begin{array}{l}\text { LH, FSH, E2 } \\
\text { tras } \\
\text { estímulo } \\
\text { VC } \\
\text { Progresión } \\
\text { de E0, peso }\end{array}$} & \multirow[t]{2}{*}{$(-)$} \\
\hline & & & & & $\begin{array}{l}\text { Leuprorelina } \\
\text { depósito } \\
11.25 \mathrm{mg} / 3 \text { meses }\end{array}$ & $\begin{array}{l}\text { Leuprorelina } \\
\text { depósito } \\
22.5 \mathrm{mg} / 3 \text { meses }\end{array}$ & 21 & 67 & 13 & 92 & & \\
\hline $\begin{array}{l}\text { Lee, et al. } \\
(2012)^{7}\end{array}$ & $\begin{array}{l}F \\
5.1-11.2 \text { años }\end{array}$ & PPC idiopática & $\begin{array}{l}\text { Pico } \mathrm{LH}>4 \\
\mathrm{UI} / \mathrm{I}\end{array}$ & ECCA & $\begin{array}{l}\text { Leuprorelina } \\
11.25 \mathrm{mg} / 3 \text { meses }\end{array}$ & $\begin{array}{l}\text { Leuprorelina } \\
30 \mathrm{mg} \mathrm{IM}\end{array}$ & 42 & 79 & 42 & 95 & $\begin{array}{l}\text { Frecuencia } \\
\text { de eventos } \\
\text { adversos }\end{array}$ & $(++)$ \\
\hline \multirow[t]{2}{*}{$\begin{array}{l}\text { Mericq, et al. } \\
(2009)^{8}\end{array}$} & \multirow[t]{2}{*}{$\begin{array}{l}F \\
8.5 \pm 1 \text { año }\end{array}$} & \multirow[t]{2}{*}{$\begin{array}{l}\text { LH }>6 \mathrm{U} / \mathrm{I} \text { post } 100 \mu \mathrm{g} \\
\text { GnRH IV } \\
\text { Tanner II antes de los } 8 \\
\text { años }\end{array}$} & \multirow[t]{2}{*}{$\begin{array}{l}\text { LH estimulada } \\
>2 \mathrm{UI} / \mathrm{I} \text { a los } 3 \\
\text { meses de } \\
\text { tratamiento }\end{array}$} & \multirow[t]{2}{*}{ ECCA } & $\begin{array}{l}\text { Leuprorelina } \\
7.5 \mathrm{mg} / \mathrm{mes}\end{array}$ & $\begin{array}{l}\text { Leuprorelina } \\
11.25 \mathrm{mg} / 3 \\
\text { meses }\end{array}$ & 5 & 60 & 4 & 50 & \multirow{2}{*}{$\begin{array}{l}\text { Cambio de } \\
\text { Tanner } \\
\text { mamario } \\
\text { Progresión } \\
\text { de la EO } \\
\text { Eventos } \\
\text { adversos }\end{array}$} & \multirow[t]{2}{*}{$(+)$} \\
\hline & & & & & $\begin{array}{l}\text { Leuprorelina } \\
11.25 \mathrm{mg} / 3 \text { meses }\end{array}$ & $\begin{array}{l}\text { Leuprorelina } \\
22.5 \mathrm{mg} / 3 \mathrm{meses}\end{array}$ & 4 & 50 & 5 & 80 & & \\
\hline $\begin{array}{l}\text { Mostafa, et al. } \\
(2014)^{9}\end{array}$ & $\begin{array}{l}\text { F y M } \\
1-11 \text { años }\end{array}$ & $\begin{array}{l}\text { Datos de PP antes de los } \\
8 \text { años en el sexo } \mathrm{F} \text { y } 9 \\
\text { años en el sexo } \mathrm{M} \\
\text { Adelanto de } \mathrm{EO}>1 \text { año, } \\
\text { pico } \mathrm{LH} \geq 8 \mathrm{UI} / \mathrm{l} \\
\text { Algunos nuevos y otros } \\
\text { tratados previamente con } \\
\text { aGnRH }\end{array}$ & $\mathrm{LH}>4 \mathrm{UI} / \mathrm{I}$ & ECCA & $\begin{array}{l}\text { Leuprorelina } \\
11.25 \mathrm{mg} / 3 \text { meses }\end{array}$ & $\begin{array}{l}\text { Leuprorelina } \\
30 \mathrm{mg} / 3 \text { meses }\end{array}$ & 24 & 86 & 24 & 97 & $\begin{array}{l}\text { Cambio de } \\
\text { Tanner } \\
\text { mamario } \\
\text { Progresión } \\
\text { de la EO } \\
\text { Eventos } \\
\text { adversos }\end{array}$ & $(+)$ \\
\hline
\end{tabular}

aGnRH: agonistas de la hormona liberadora de gonadotropina; E2: estradiol; ECCA: ensayo clínico controlado aleatorizado; E0: edad ósea; F: femenino; FSH: hormona estimulante del folicấlo; GnRH: hormona liberadora de gonadotropina; IM: intramuscular; LH: hormona luteinizante; M: masculino; PP: pubertad precoz; PPC: pubertad precoz central. 
Tabla 3. Efectos a largo plazo del tratamiento con aGnRH: estudios observacionales

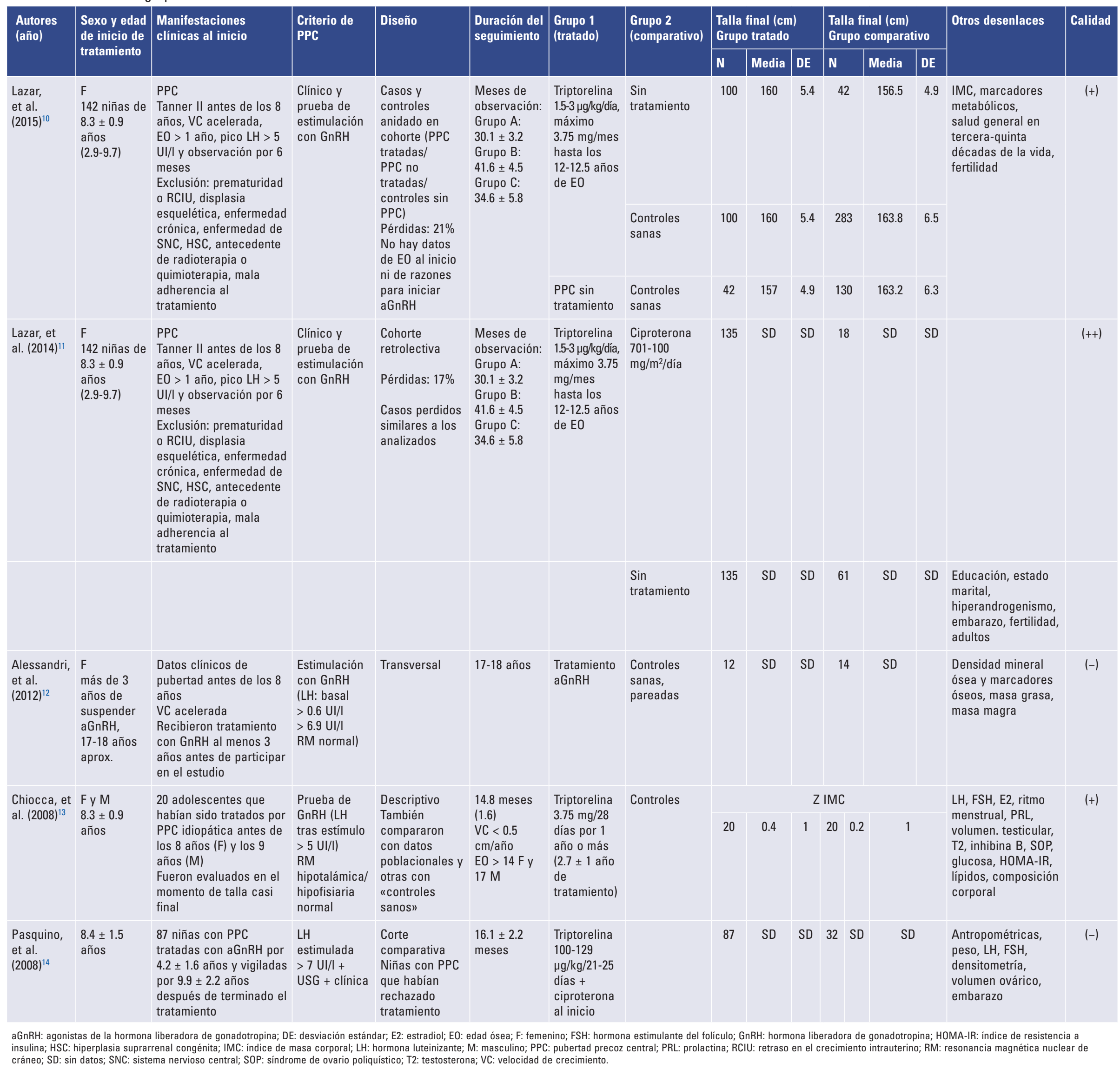


Tabla 4. Estudios que evalúan desenlaces psicosociales en sujetos con pubertad precoz

\begin{tabular}{|c|c|c|c|c|}
\hline Autores (año) & País & Diseño & Objetivos & Hallazgos \\
\hline $\begin{array}{l}\text { Xhrouet- } \\
\text { Heinrichs, et al. } \\
(1997)^{15}\end{array}$ & Bélgica & $\begin{array}{l}20 \text { niñas con antecedente de PPC, } 15 \\
\text { idiopática y } 5 \text { secundaria a lesiones del } \\
\text { SNC resueltas o controladas; } 15 \text { tratadas } \\
\text { y } 5 \text { no tratadas (no aleatorizado) } \\
\text { Cualitativo (entrevista semiestructurada) } \\
\text { y cuestionarios estandarizados }\end{array}$ & $\begin{array}{l}\text { Describir aspectos psicológicos de las } \\
\text { niñas con PPC y sus familias al } \\
\text { diagnóstico y } 24 \text { meses después }\end{array}$ & $\begin{array}{l}\text { Los aspectos de la pubertad que preocupaban a padre, madre, } \\
\text { endocrinólogo y pacientes frecuentemente fueron distintos } \\
\text { El motivo de preocupación más frecuente en las niñas era la } \\
\text { vergüenza por los cambios físicos perceptibles por sus pares (i.e., } \\
\text { crecimiento mamario). Un motivo frecuente de preocupación en las } \\
\text { madres era la llegada de la menstruación; a los endocrinólogos les } \\
\text { preocupaba más la talla final. Padres, madres y pacientes } \\
\text { expresaron temor por la sexualidad } \\
\text { Al inicio de la PPC tuvieron puntajes altos en las escalas de } \\
\text { retraimiento, ansiedad y depresión de la Child Behavior Checklist que } \\
\text { tendían a mejorar a los } 2 \text { años }\end{array}$ \\
\hline $\begin{array}{l}\text { Kelly, et al. } \\
(2017)^{16}\end{array}$ & Reino Unido & Cohorte desde la infancia & $\begin{array}{l}\text { Asociación entre nivel socioeconómico, } \\
\text { tipo étnico y PP } \\
\text { Asociación de PP con obesidad } \\
\text { Asociación de estrés psicosocial y PP }\end{array}$ & $\begin{array}{l}\text { La pobreza en la infancia se asocia a pubertad temprana. Aunque } \\
\text { disminuye la fuerza de la asociación, esta se mantiene si se ajusta } \\
\text { por el IMC e indicadores de estrés psicosocial } \\
\text { Pubertad más temprana en niñas con ascendencia india, y no hay } \\
\text { cambios con ajuste para covariables } \\
\text { Pubertad más temprana también en niñas de ascendencia de } \\
\text { Pakistán, Bangladesh y raza negra; la asociación se atenúa al ajustar } \\
\text { por covariables }\end{array}$ \\
\hline Lee, et al. $(2016)^{17}$ & Hong Kong & $\begin{array}{l}\text { Cohorte (?) en niños de secundaria, } \\
\text { aunque más bien parece transversal }\end{array}$ & $\begin{array}{l}\text { Asociación entre pubertad temprana } \\
\text { (Tanner }+1 \text { DE, autorreportada) y } \\
\text { comportamientos de riesgo antes de los } \\
20 \text { años } \\
\text { Asociación entre menarca temprana } \\
\text { (< } 10 \text { años) y comportamientos de riesgo }\end{array}$ & $\begin{array}{l}\text { Las niñas con pubertad temprana fuman más y tienen mayor } \\
\text { actividad sexual } \\
\text { Los comportamientos de riesgo no se asocian con la edad de la menarca } \\
\text { No hay asociación entre pubertad temprana y consumo de alcohol } \\
\text { En el análisis multivariado solo permanece la asociación entre } \\
\text { actividad sexual y pubertad tardía como factor protector } \\
\text { El riesgo de depresión es similar entre los grupos } \\
\text { El comportamiento "problemático" es similar entre los grupos }\end{array}$ \\
\hline $\begin{array}{l}\text { Mensah, et al. } \\
(2013)^{18}\end{array}$ & Australia & Cohorte desde los 4 hasta los 11 años & $\begin{array}{l}\text { Asociación entre pubertad temprana } \\
(\leq 8-9 \text { años) y el Total Difficulties Score } \\
\text { y calidad de vida antes, durante y } \\
\text { después de la pubertad }\end{array}$ & $\begin{array}{l}\text { Los varones con pubertad temprana tenían mayor puntaje de Total } \\
\text { Difficulties } S c o r e \text { a los } 4,6,8 \text { y } 10 \text { años } \\
\text { Niños y niñas con pubertad temprana tuvieron menos calidad de vida } \\
\text { a los } 4,6,8 \text { y } 10 \text { años } \\
\text { Total Difficulties Score y } Q 0 L \text { se correlacionan a lo largo de las } \\
\text { cuatro mediciones }\end{array}$ \\
\hline $\begin{array}{l}\text { Copeland, et al. } \\
(2010)^{19}\end{array}$ & Reino Unido & Cohorte & $\begin{array}{l}\text { Asociación entre pubertad temprana } \\
\text { (Tanner IV }<12 \text { años o menarca }<11 \\
\text { años) y desenlaces en la adolescencia } \\
\text { (13-16 años) } \\
\text { Asociación entre pubertad temprana y } \\
\text { desenlaces en la edad adulta temprana } \\
\text { (19-21 años) }\end{array}$ & $\begin{array}{l}\text { En la adolescencia, las maduradoras tempranas tienen más } \\
\text { infracciones autorreportadas (aunque no más criminalidad global), } \\
\text { abuso o dependencia de alcohol, marihuana, drogas iĺcitas, } \\
\text { comportamientos de riesgo asociados a sustancias, problemas } \\
\text { sociales con pares, fuga de casa, inicio de actividad sexual y } \\
\text { trastornos psiquiátricos (depresión y conducta) entre los } 13 \text { y } 16 \text { años } \\
\text { Las maduradoras tempranas tienen menos abuso/dependencia de } \\
\text { drogas ilícitas a los } 19-21 \text { años que el resto de las adolescentes; } \\
\text { tienen un mayor número de parejas sexuales en la vida y más } \\
\text { frecuencia de depresión } \\
\text { Si se analiza solo el grupo con «más problemas en la adolescencia», } \\
\text { los resultados en la adultez son prácticamente iguales }\end{array}$ \\
\hline $\begin{array}{l}\text { Michaud, et al. } \\
(2006)^{20}\end{array}$ & Suiza & Transversal & $\begin{array}{l}\text { Asociación entre pubertad percibida } \\
\text { como temprana respecto a sus } \\
\text { compañeros y desenlaces a los } 16-20 \\
\text { años }\end{array}$ & $\begin{array}{l}\text { Niñas con pubertad temprana fumaban con más frecuencia, mayor } \\
\text { frecuencia de ser sexualmente activas, más victimizadas, con más } \\
\text { síntomas funcionales e insatisfechas con su imagen corporal } \\
\text { Pubertad temprana más frecuente en las ciudades y en los migrantes } \\
\text { Niños con pubertad temprana tenían más desenlaces psicosociales } \\
\text { adversos }\end{array}$ \\
\hline $\begin{array}{l}\text { Johansson y } \\
\text { Ritzen }(2005)^{21}\end{array}$ & Suiza & Cohorte & & $\begin{array}{l}\text { A los } 43 \text { años, las adultas que tuvieron pubertad temprana son, en } \\
\text { promedio, } 3 \mathrm{~cm} \text { más bajas y con un peso ligeramente mayor, pero su } \\
\text { satisfacción global y su calidad de vida son iguales que las de } \\
\text { aquellas que tuvieron pubertad normal }\end{array}$ \\
\hline $\begin{array}{l}\text { Baumann, et al. } \\
(2001)^{22}\end{array}$ & Alemania & $\begin{array}{l}\text { Cohorte descriptivo y cualitativo } \\
\mathrm{F}(?)(\mathrm{n}=19) \\
\text { Rechazaron participar } 2 / 21 \text { Edad de } \\
\text { inicio de pubertad } 4.5 \pm 1.9 \text { años }(1.5-8.0) \\
\text { Todas tratadas con aGnRH } \\
\text { Entrevistadas a los } 18.1 \pm 2.7 \text { años } \\
(14.3-21.9)\end{array}$ & Evaluar experiencia psicológica de la PP & $\begin{array}{l}\text { Talla final } 160.9 \pm 6.7 \mathrm{~cm}(147-178 \mathrm{~cm}) \\
\text { Durante el tratamiento se presentaron sentimientos de inseguridad } \\
(63 \%) \text {, vergüenza }(47 \%) \text {, retraimiento frecuente }(21 \%) \text {, alta frecuencia } \\
\text { de señalamientos sobre caracteres sexuales por sus pares }(32 \%) \text {, } \\
\text { temor de talla final baja }(47 \%) \text {, satisfacción con la talla presente }(74 \%) \\
\text { Alta puntuación en «problemas internalizados de comportamiento" } \\
\text { (retraimiento, ansiedad/depresión y malestar físico) de la Child } \\
\text { Behavior Checklist, más elevado que parámetros normativos. Sin } \\
\text { diferencia en uproblemas externalizados" (sociales, atención, } \\
\text { criminalidad, agresividad). Sin diferencia en autoestima e imagen } \\
\text { corporal con el Questionnaire of Body Experience (FBeK) } \\
\text { La edad al inicio de la pubertad se asoció con el desajuste } \\
\text { psicológico (a mayor edad de inicio, peor ajuste) } \\
\text { La estatura adulta se asoció con el ajuste psicológico (a mayor } \\
\text { estatura, mejor ajuste) }\end{array}$ \\
\hline $\begin{array}{l}\text { Schoevaart, et al. } \\
(1990)^{23}\end{array}$ & Países Bajos & $\begin{array}{l}\text { Transversal, cualitativo (entrevista } \\
\text { estructurada) a los } 16-26 \text { años }(n=34 ; 27 \\
\text { niñas y } 7 \text { niños) } \\
\text { Tratamiento: } 22 \text { con ciproterona, } 3 \text { con } \\
\text { medroxiprogesterona y } 9 \text { sin tratamiento }\end{array}$ & Evaluar aspectos psicológicos de la PP & $\begin{array}{l}\text { No se encontró asociación entre el tratamiento y el bienestar en la } \\
\text { edad adulta o la repercusión psicológica }\end{array}$ \\
\hline $\begin{array}{l}\text { Jackson y Ott } \\
(1990)^{24}\end{array}$ & $\begin{array}{l}\text { Estados } \\
\text { Unidos }\end{array}$ & Cuantitativo-cualitativo & Evaluar autoestima en niñas con PPC & $\begin{array}{l}\text { El estudio cuantitativo no mostró diferencias en las escalas de } \\
\text { autoestima } \\
\text { El estudio cualitativo sugiere mayores niveles de ansiedad y de } \\
\text { relación con amigos }\end{array}$ \\
\hline $\begin{array}{l}\text { Nacinovich, et al. } \\
(2016)^{25}\end{array}$ & Italia & $\begin{array}{l}\text { Transversal } \\
\text { Niños y niñas con PP y pubertad } \\
\text { temprana (7-15 años) }\end{array}$ & $\begin{array}{l}\text { Evaluar la calidad de las experiencias } \\
\text { corporales y aspectos psicológicos en } \\
\text { niñas y niños con PP y pubertad } \\
\text { temprana }\end{array}$ & $\begin{array}{l}\text { Más depresión en niñas con PP y pubertad temprana, e imagen } \\
\text { corporal más negativa }\end{array}$ \\
\hline $\begin{array}{l}\text { Schoelwer, et al. } \\
(2017)^{26}\end{array}$ & $\begin{array}{l}\text { Estados } \\
\text { Unidos }\end{array}$ & $\begin{array}{l}\text { Cohorte de un año con PP, pubertad } \\
\text { temprana y adrenarca precoz } \\
\text { Todos los casos de PPC tratadas con } \\
\text { aGnRH } \\
\text { Childs Depression Inventory, Harter } \\
\text { Pictorial Scale of Perceived Competence } \\
\text { and Social Acceptance for Young } \\
\text { Children, Child Behavior Checklist }\end{array}$ & $\begin{array}{l}\text { Evaluar si las características } \\
\text { psicológicas de las niñas con variantes } \\
\text { de pubertad temprana y de sus madres } \\
\text { cambian en el tiempo y con el } \\
\text { tratamiento para PPC }\end{array}$ & $\begin{array}{l}\text { La percepción de autocompetencia baja con el tiempo y la } \\
\text { percepción de la aceptación materna sube. En general, no hay } \\
\text { diferencias con datos normativos, excepto para competencia física }\end{array}$ \\
\hline Mul, et al. $(2001)^{27}$ & Países Bajos & $\begin{array}{l}\text { ECA } \\
\text { Pubertad temprana en niños adoptados } \\
(n=30), \text { aGnRH vs. aGnRH }+\mathrm{GH} \text { con } \\
\text { evaluaciones antes/después }\end{array}$ & $\begin{array}{l}\text { Evaluar el efecto psicológico de la } \\
\text { pubertad temprana y la talla baja y del } \\
\text { tratamiento }\end{array}$ & $\begin{array}{l}\text { En niños adoptados con pubertad temprana y pronóstico de estatura } \\
\text { bajo, los problemas emocionales o de conducta, la autopercepción y } \\
\text { el estrés son similares a los de la población general. El tratamiento } \\
\text { con aGnRH con o sin GH no cambió el estado }\end{array}$ \\
\hline
\end{tabular}
evaluaciones antes/después $\quad$ con aGnRH con 0 sin $\mathrm{GH}$ no cambió el estado 
María F. Castilla-Peón, et al.: Pubertad precoz: síntesis de la evidencia (Anexo)

Tabla 5. Ensayos clínicos que evaluaron el efecto de la hormona de crecimiento como cointervención a un aGnRH en la talla final

\begin{tabular}{|c|c|c|c|c|c|c|c|c|c|c|c|c|c|c|c|}
\hline \multirow[t]{2}{*}{$\begin{array}{l}\text { Autores } \\
\text { (año) }\end{array}$} & \multirow[t]{2}{*}{ Población } & \multirow[t]{2}{*}{$\begin{array}{l}\text { Criterios de } \\
\text { inclusión }\end{array}$} & \multirow[t]{2}{*}{ Diseño } & \multirow{2}{*}{$\begin{array}{l}\text { Criterios } \\
\text { para fin de } \\
\text { tratamiento }\end{array}$} & \multirow[t]{2}{*}{ Intervención } & \multirow[t]{2}{*}{ Comparativo } & \multicolumn{3}{|c|}{$\begin{array}{l}\text { Grupo intervención } \\
\text { (cm) }\end{array}$} & \multicolumn{3}{|c|}{$\begin{array}{l}\text { Grupo control } \\
\text { (cm) }\end{array}$} & \multirow[t]{2}{*}{$\begin{array}{l}\text { Diferencia } \\
\text { (cm) }\end{array}$} & \multirow[t]{2}{*}{$\begin{array}{l}\text { Otros } \\
\text { desenlaces }\end{array}$} & \multirow[t]{2}{*}{ Calidad } \\
\hline & & & & & & & N & Media & DE & $\mathbf{N}$ & Media & DE & & & \\
\hline $\begin{array}{l}\text { Mul, et al. } \\
(2005)^{28}\end{array}$ & $\begin{array}{l}\text { F } \\
\text { Grupo A: } 9.7 \\
\pm 0.9 \text { años } \\
\text { Grupo B: } 9.6 \\
\pm 0.9 \text { años }\end{array}$ & $\begin{array}{l}\text { Pubertad 7-10 años, } \\
\text { menarca, E0 < 12.5, } \\
\text { pronóstico de talla } \\
\text { final }<\text { p3, prueba } \\
\text { de estimulación } \\
\text { con GnRH positiva }\end{array}$ & $\begin{array}{l}\text { ECCA } \\
\text { Aunque } \\
\text { aleatorizado, el } \\
\text { grupo con } \mathrm{GH} \\
\text { tenía menor PAH } \\
(3-5 \mathrm{~cm})\end{array}$ & $\begin{array}{l}E 0>15 \text { años } \\
\text { o } V C<1 \mathrm{~cm} / \\
\text { año }\end{array}$ & $\begin{array}{l}\text { Triptorelina } \\
3.75 \mathrm{mg} / 28 \text { días } \\
+\mathrm{GH} \\
1.33 \mathrm{mg} / \mathrm{m}^{2} \text { por } \\
3 \text { años }\end{array}$ & $\begin{array}{l}\text { Triptorelina } \\
3.75 \mathrm{mg} / 28 \\
\text { días por } 3 \\
\text { años }\end{array}$ & 14 & 155 & 5.5 & 12 & 155 & 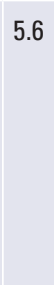 & 0 & $\begin{array}{l}\text { Delta talla } \\
\text { final-PTF } \\
\text { EO } \\
\text { Niveles de } \\
\text { IGF-1 e } \\
\text { IGFBP3 } \\
\text { Niveles de } \\
\text { andrógenos }\end{array}$ & $(+)$ \\
\hline $\begin{array}{l}\text { Pasquino, } \\
\text { et al. } \\
(1999)^{29}\end{array}$ & $\begin{array}{l}\mathrm{F} \\
10 \text { pacientes } \\
\text { con PPC }\end{array}$ & SD & $\begin{array}{l}\text { Comparativo no } \\
\text { aleatorizado }\end{array}$ & $\begin{array}{l}E C \approx 14 \text { años } \\
E O>15 \text { años } \\
V C< \\
1 \mathrm{~cm} / \text { año }\end{array}$ & $\begin{array}{l}\text { Triptorelina } \\
100 \mu \mathrm{g} / \mathrm{kg} / 21 \\
\text { días } \mathrm{IM}+\mathrm{GH} \\
0.3 \mathrm{mg} / \mathrm{kg} / \\
\text { semana, } 6 / 7 \\
\text { días a la } \\
\text { semana por } 2-3 \\
\text { años }\end{array}$ & $\begin{array}{l}\text { Triptorelina } \\
100 \mu \mathrm{g} / \mathrm{kg} / 21 \\
\text { días IM }\end{array}$ & 10 & 160.6 & 1.3 & 10 & 155.1 & 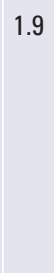 & 5.5 & & $(-)$ \\
\hline $\begin{array}{l}\text { Pucarelli, } \\
\text { et al. } \\
(2003)^{30}\end{array}$ & $\begin{array}{l}\text { F } \\
\text { Grupo A: } 8.3 \\
\pm 1.6 \text { años } \\
\text { Grupo } \\
\text { B: } 9 \pm 0.8 \\
\text { años }\end{array}$ & $\begin{array}{l}\text { Niñas PPC y VC } \\
<\text { p25; sin mejoría } \\
\text { en pronóstico de } \\
\text { talla }\end{array}$ & $\begin{array}{l}\text { Comparativo con } \\
\text { quienes } \\
\text { rechazaron } \\
\text { tratamiento, no } \\
\text { aleatorizado }\end{array}$ & $\begin{array}{l}\text { EO > } 13 \text { y VC } \\
<1 \mathrm{~cm} / \text { año } \\
\text { Grupo A: } 16.1 \\
\pm 2.4 \text { años } \\
\text { Grupo B: } 15.4 \\
\pm 1.7 \text { años }\end{array}$ & $\begin{array}{l}\text { Triptorelina } \\
100 \mu \mathrm{g} / \mathrm{kg} \mathrm{c} / 21 \\
\text { días }+\mathrm{GH} 0.3 \\
\mathrm{mg} / \mathrm{kg} / \mathrm{semana}\end{array}$ & $\begin{array}{l}\text { Triptorelina } \\
100 \mu \mathrm{g} / \mathrm{kg} / 21 \\
\text { días }\end{array}$ & 17 & 161.2 & 4.8 & 18 & 156.6 & 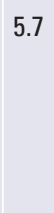 & 4.6 & $\begin{array}{l}\text { Eventos } \\
\text { adversos } \\
\text { en perfil de } \\
\text { lípidos o } \\
\text { glucemia }\end{array}$ & $(-)$ \\
\hline $\begin{array}{l}\text { Tuvemo, } \\
\text { et al. } \\
(2004)^{31}\end{array}$ & $\begin{array}{l}\text { F } \\
\text { Menores de } \\
9.5 \text { años } \\
\text { Grupo A: } 8.4 \\
\pm 0.78 \text { años } \\
\text { Grupo B: } 8.2 \\
\pm 0.83 \text { años }\end{array}$ & $\begin{array}{l}\text { Adoptadas de } \\
\text { países en vías de } \\
\text { desarrollo } \\
\text { Tanner mamario II } \\
\text { o III } \\
\text { Tanner púbico } \geq 2 \text { o } \\
\text { VC } \geq 6 \mathrm{~cm} / \text { año } \\
\text { TSH normal }\end{array}$ & ECCA & No es claro & $\begin{array}{l}\text { Buserelina } \\
300 \mu \mathrm{g} \\
6 \mathrm{veces} / \mathrm{día} \\
+\mathrm{GH} \\
0.033 \mu \mathrm{g} / \mathrm{kg} / \mathrm{día} \\
\mathrm{SC} \text { por } 7 \text { días a } \\
\text { la semana } \\
\text { Buserelina se } \\
\text { dio como } \\
\text { implante } \\
\text { después del } \\
\text { segundo año }\end{array}$ & $\begin{array}{l}\text { Buserelina } \\
300 \mu \mathrm{g} 6 \\
\text { veces/día } \\
\text { (spray nasal) }\end{array}$ & 24 & 158.9 & 5.36 & 22 & 155.8 & 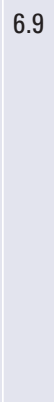 & 3.1 & $\begin{array}{l}Z \text { talla } \\
\text { antes- } \\
\text { después }\end{array}$ & $(+)$ \\
\hline
\end{tabular}

aGnRH: agonistas de la hormona liberadora de gonadotropinas; DE: desviación estándar; EC: edad cronológica; ECCA: ensayo clínico controlado aleatorizado; EO: edad ósea; F: femenino; GH: hormona de crecimiento; IGF-1: factor de crecimiento similar a la insulina, tipo 1; IGFBP3: proténa ligadora de factor de crecimiento similar a la insulina tipo 3; IM: intramuscular; PAH: predicción de talla adulta; PPC: pubertad precoz central; PTF: prededicción de talla final; SC: subcutáneo; SD: sin
datos; TSH: hormona estimulante de la tiroides; VC: velocidad de crecimiento. 
Bol Med Hosp Infant Mex. 2020;77Supl(1)

Tabla 6. Estudios que evaluaron el efecto de intervenciones distintas a los aGnRH en la talla de sujetos con pubertad precoz central

\begin{tabular}{|c|c|c|c|c|c|c|c|c|c|c|c|c|c|}
\hline \multirow[t]{2}{*}{ Autores (año) } & \multirow[t]{2}{*}{ Población } & \multirow[t]{2}{*}{ Criterios de inclusión } & \multirow[t]{2}{*}{ Diseño } & \multirow[t]{2}{*}{ Intervención } & \multirow[t]{2}{*}{ Comparativo } & \multicolumn{3}{|c|}{ Grupo intervención } & \multicolumn{3}{|c|}{ Grupo control } & \multirow{2}{*}{$\begin{array}{l}\text { Otros } \\
\text { desenlaces }\end{array}$} & \multirow[t]{2}{*}{ Calidad } \\
\hline & & & & & & $\mathbf{N}$ & Media & DE & $\mathbf{N}$ & Media & DE & & \\
\hline $\begin{array}{l}\text { Antoniazzi, et } \\
\text { al. }(2003)^{32}\end{array}$ & $\begin{array}{l}\mathrm{F} \\
48 \text { niñas de } \\
7.19 \pm 0.96 \text { años }\end{array}$ & $\begin{array}{l}\text { Tanner mamario o } \\
\text { púbico II; prueba GnRH } \\
\text { positiva }\end{array}$ & ECCA & $\begin{array}{l}\text { Triptorelina } \\
3.75 \mathrm{mg} / \mathrm{mes} \text { por } \\
3.88 \pm 1.3 \text { años }+ \text { calcio } 1 \mathrm{~g} / \text { día } \\
\text { por } 2.89 \pm 0.59 \text { años }\end{array}$ & $\begin{array}{l}\text { Triptorelina } \\
3.75 \mathrm{mg} / \mathrm{mes} \text { por } \\
4.08 \pm 1.28 \text { años }\end{array}$ & 21 & 159.4 & 6.2 & 27 & 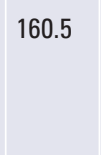 & 5.4 & $\begin{array}{l}\text { Densidad } \\
\text { mineral ósea } \\
\text { cerca de los } 16 \\
\text { años }\end{array}$ & $(++)$ \\
\hline $\begin{array}{l}\text { Abodovsky, et } \\
\text { al. }(1979)^{33}\end{array}$ & $\begin{array}{l}F \\
16 \text { niñas de } \\
12 \text { meses a } 9.5 \\
\text { años }\end{array}$ & $\begin{array}{l}\text { Datos clínicos y de } \\
\text { laboratorio }\end{array}$ & $\begin{array}{l}\text { Descriptivo } \\
\text { (no } \\
\text { comparativo) } \\
\text { Dosis y } \\
\text { periodos de } \\
\text { tratamiento } \\
\text { variables }\end{array}$ & $\begin{array}{l}\text { Acetato de medroxiprogesterona } \\
150-300 \mathrm{mg} / 15-20 \text { días por } 5 \\
\text { meses a } 6 \text { años }\end{array}$ & Sin comparador & SD & SD & SD & SD & 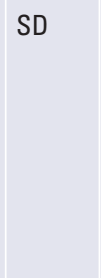 & SD & $\begin{array}{l}\text { PTF: talla para } \\
\text { EO, delta talla/ } \\
\text { delta EO por } \\
\text { año, cociente } \\
\text { de desarrollo }\end{array}$ & $(-)$ \\
\hline $\begin{array}{l}\text { Karamizadeh y } \\
\text { Mohammadi, } \\
(2012)^{34}\end{array}$ & $\begin{array}{l}F \\
36 \text { niñas } \\
\text { Dos grupos: } \\
106.7 \pm 10.57 \text { y } \\
102.7 \pm 13.7 \\
\text { meses de edad }\end{array}$ & & $\begin{array}{l}\text { ECCA } \\
\text { (presentación } \\
\text { en congreso) }\end{array}$ & $\begin{array}{l}\text { aGnRH + vitamina A } 6000 \mathrm{U} / \\
\text { semana y hierro } 10 \mathrm{mg} / \mathrm{día}\end{array}$ & aGnRH solo & 19 & SD & SD & 17 & 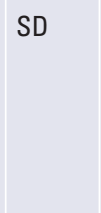 & SD & $\begin{array}{l}\text { zVC, zTalla, } \\
\text { zPTF }\end{array}$ & $(-)$ \\
\hline \multirow[t]{4}{*}{$\begin{array}{l}\text { Papadimitriou, } \\
\text { et al. }(2016)^{35}\end{array}$} & \multirow{4}{*}{$\begin{array}{l}\mathrm{F} \\
40 \text { niñas } \\
\text { de } 7.5-9 \text { años } \\
\text { con desarrollo } \\
\text { mamario }\end{array}$} & \multirow{4}{*}{$\begin{array}{l}\text { E2 } \geq 15 \mathrm{pg} / \mathrm{ml} \text {, longitud } \\
\text { uterina } \geq 35 \mathrm{~mm}, \\
\text { ovarios } \geq 3 \mathrm{~cm}^{3} \\
\text { zPTF }<-1.5 \mathrm{DE} \text { que TBF, } \\
\text { zPTF }<-2 \text { o } 1.5 \mathrm{DE} \text { que } \\
\text { TBF } \\
\text { Prueba de estimulación } \\
\text { con aGnRH }\end{array}$} & \multirow{4}{*}{$\begin{array}{l}\text { ECCA } \\
\text { La z talla al } \\
\text { inicio era } \\
\text { menor en el } \\
\text { grupo de } \\
\text { intervención } \\
\text { y con mayor } \\
\text { PTF al inicio }\end{array}$} & \multirow{4}{*}{$\begin{array}{l}\text { Leuprorelina } \\
0.3 \mathrm{mg} / \mathrm{kg} / \mathrm{mes} \mathrm{SC/IM} \mathrm{+} \\
\text { anastrozol } 1 \mathrm{mg} / \mathrm{dí} a\end{array}$} & \multirow{4}{*}{$\begin{array}{l}\text { Leuprorelina } \\
0.3 \mathrm{mg} / \mathrm{kg} / \mathrm{mes} \\
\mathrm{SC} / \mathrm{IM}\end{array}$} & \multicolumn{6}{|c|}{ zPTF a los 24 meses de tratamiento } & \multirow{4}{*}{$\begin{array}{l}\text { Talla, VC, delta } \\
\text { EO, TBF-PTF, } \\
\text { ganancia en } \\
\text { PTF a los } 6,12, \\
18 \text { y } 24 \text { meses }\end{array}$} & \multirow[t]{4}{*}{$(+)$} \\
\hline & & & & & & 10 & 1.05 & 0.9 & 11 & & 0 & & \\
\hline & & & & & & \multicolumn{6}{|c|}{ Ganancia en zPAH a los 24 meses } & & \\
\hline & & & & & & 10 & 1.21 & 0.45 & 11 & 0.31 & 0 & & \\
\hline $\begin{array}{l}\text { Roth, et al. } \\
(2005)^{36}\end{array}$ & $\begin{array}{l}\text { F y M } \\
\text { Niñas y niños } \\
\text { de } 4.3-10.2 \\
\text { años }\end{array}$ & $\begin{array}{l}\text { Tanner mamario II antes } \\
\text { de los } 8 \text { años } \\
\text { Tanner genital II en } \\
\text { niños (volumen } \\
\text { testicular }>3 \mathrm{~cm}^{3} \text { ) antes } \\
\text { de los } 9 \text { años } \\
\text { EO adelantada y prueba } \\
\text { de GnRH positiva }\end{array}$ & ECCA & $\begin{array}{l}\text { GnRH antagonista ( } 3 \text { dosis SC } \\
\text { c/72 h) }+ \text { aGnRH }\end{array}$ & aGnRH solo & 6 & SD & SD & 4 & 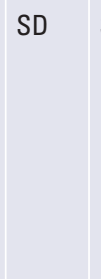 & SD & $\begin{array}{l}\text { Supresión de } \\
\text { pico de LH } \\
\text { urinaria y } \\
\text { sérica }\end{array}$ & $(+)$ \\
\hline
\end{tabular}

aGnRH: agonistas de la hormona liberadora de gonadotropinas; DE: desviación estándar; E2: estradiol; ECCA: ensayo clínico controlado aleatorizado; E0: edad ósea; F: femenino; IM: intramuscularñ LH: hormona luteinizante; M: masculino; PTF: predicción de talla final; SC: subcutáneo; SD: sin datos; TBF: talla blanco familiar; VC: velocidad de crecimiento. 


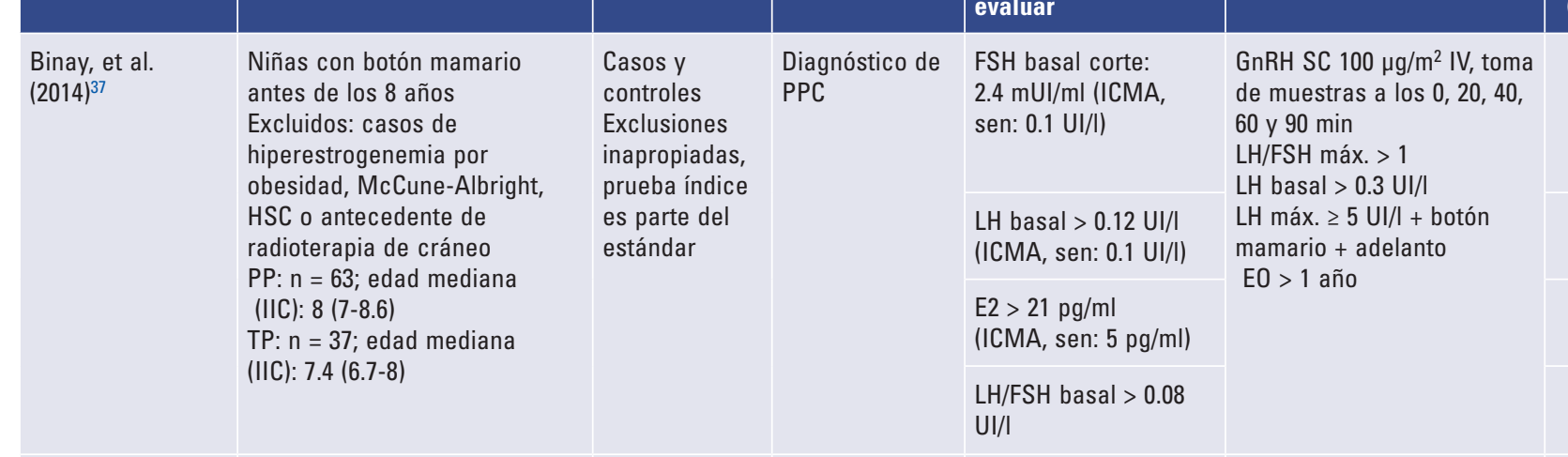

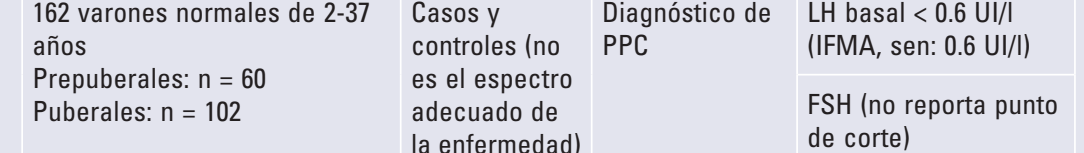

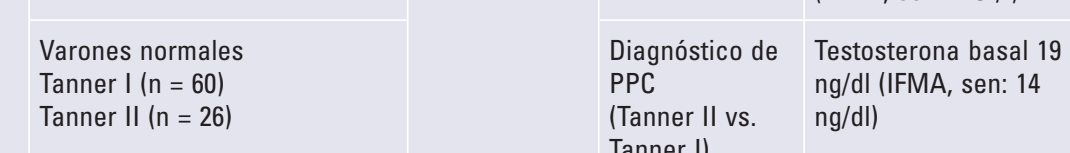

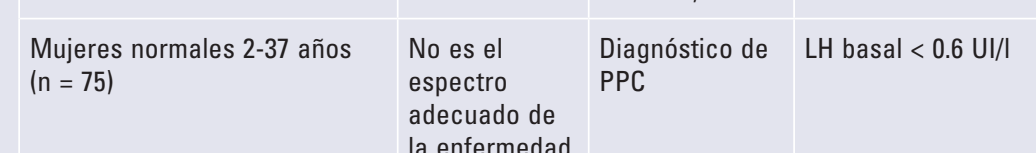

FSH basal (no reporta
punto de corte)

E2 basal $>13.6 \mathrm{pg} / \mathrm{ml}$
(IFMA,

61 So $\quad$ SD $\quad$ SD

sen: $13.6 \mathrm{pg} / \mathrm{mll}$

Varones con «pubertal
precozon

LH basal 0.6 UIII

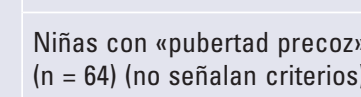

LH basal 0.6 UII

$\begin{aligned} & \text { Varones normales } \\ & \text { de } 2-37 \text { años }\end{aligned}$
a

E2 $>13.6 \mathrm{pg} / \mathrm{mm}$

Mujeres normales
de $2-39$ años

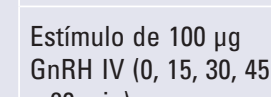

Pico $>9.6$ UIII

Varones con «pubertad
precoz»"

Pico $\mathrm{LH}>6.9$ UIII

Niñas con npubertad precozp
(n= 644$)$ (no señanalan criterios)

Pico L $L$ > $9.6 \mathrm{UIII}$

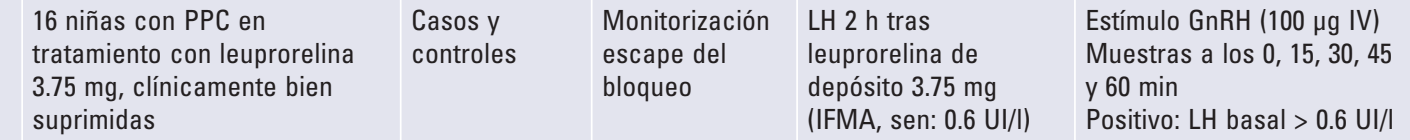

Brito, et
$2004)^{9}$

Pico LH $>6.9$ U/I

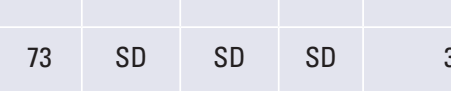

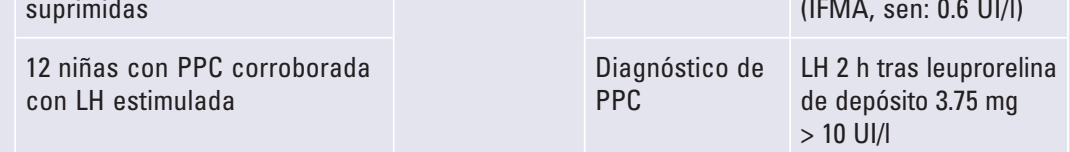

$\begin{array}{lllll}76 & \text { SD } & \text { SD } & \text { SD } & 75\end{array}$

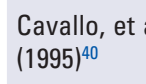

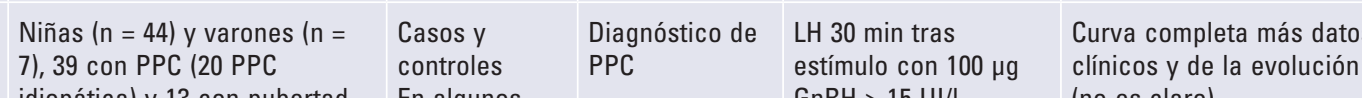

31 SD $\quad$ SD $\quad$ SD $\quad 75$

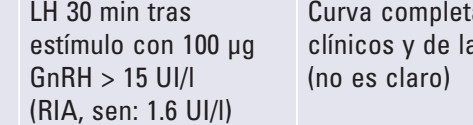

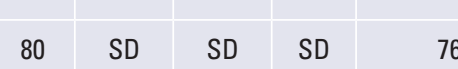

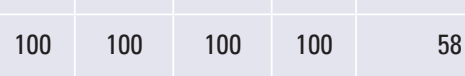

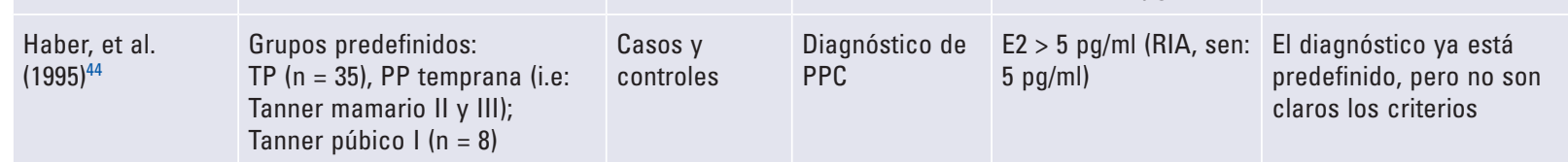

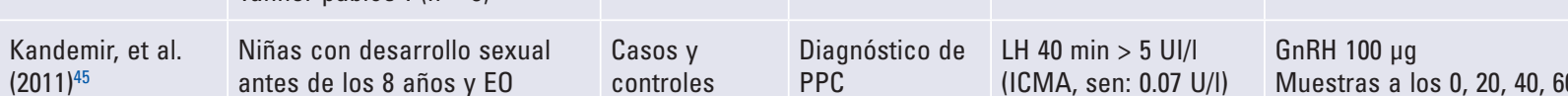

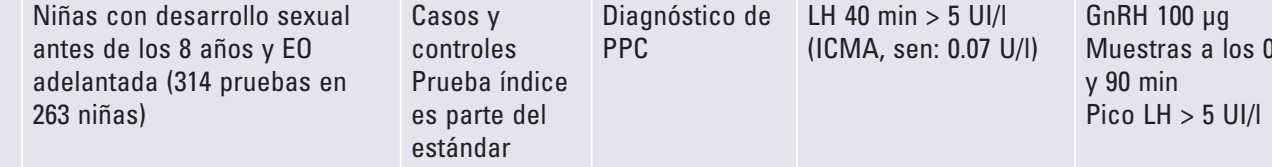

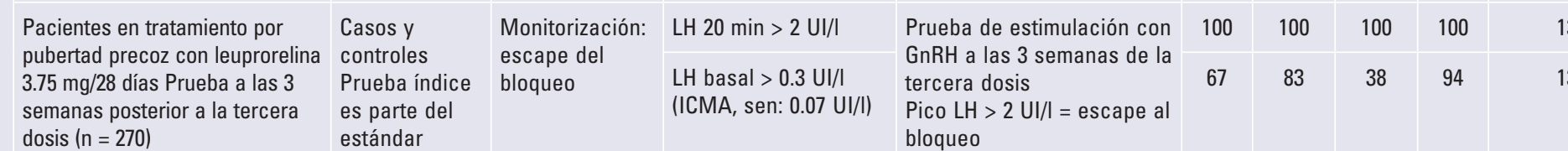

\begin{tabular}{l|l|l|l|l|}
94 & 87 & 95 & 86 & 71 \\
\hline 9 & 94 & 97 & 83 & 1
\end{tabular}

$\begin{array}{llllll}95 & 81 & 92 & 87 & 71\end{array}$

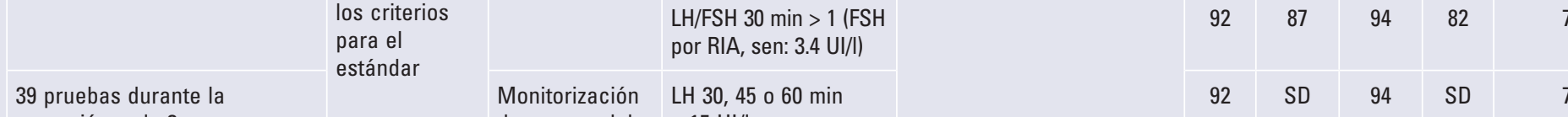

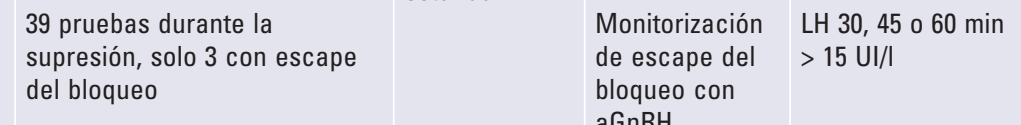

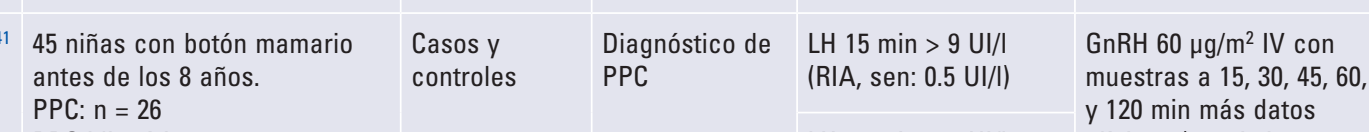

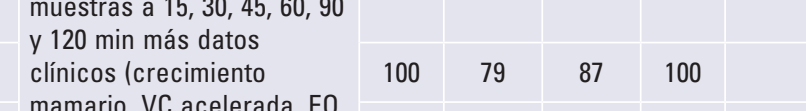

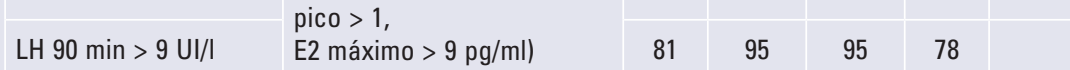

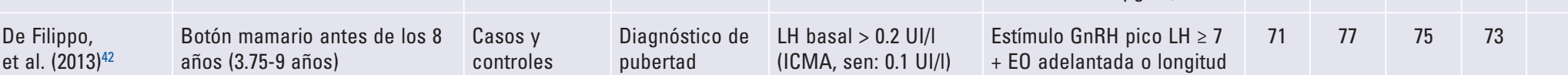

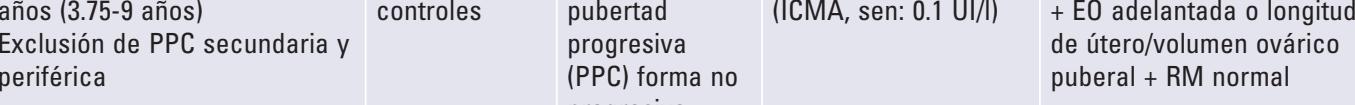

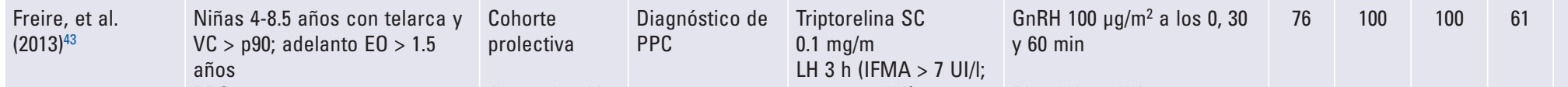

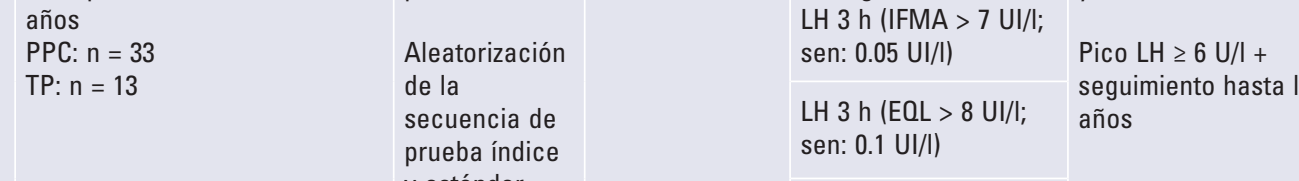
E2 $24 \mathrm{~h}>295 \mathrm{pmol}(80$
$\mathrm{pg} /()(E \mathrm{ELL}$, sen: 36.7

LH 3 h IIFMA $>7$ UU)

$\stackrel{0}{E} 224 \mathrm{~h}>80$ pg/ll

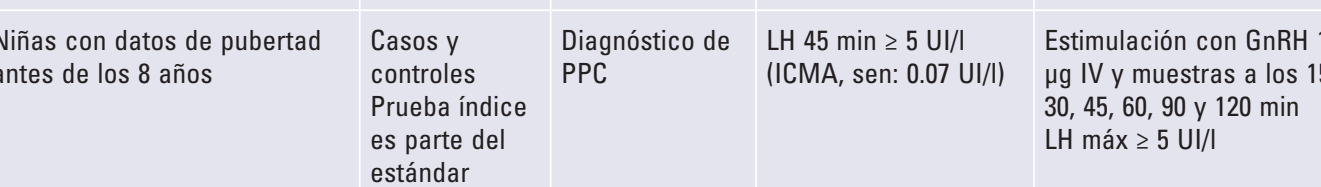

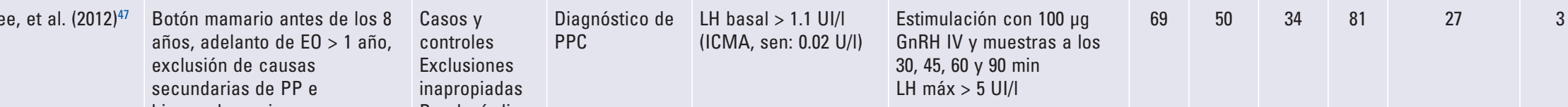

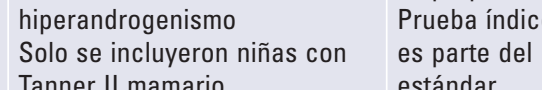

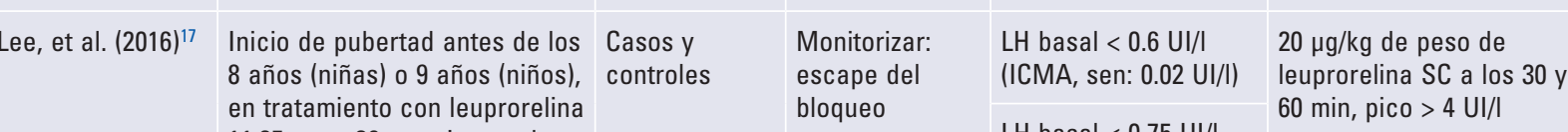

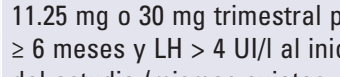

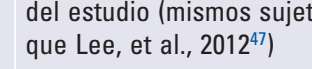

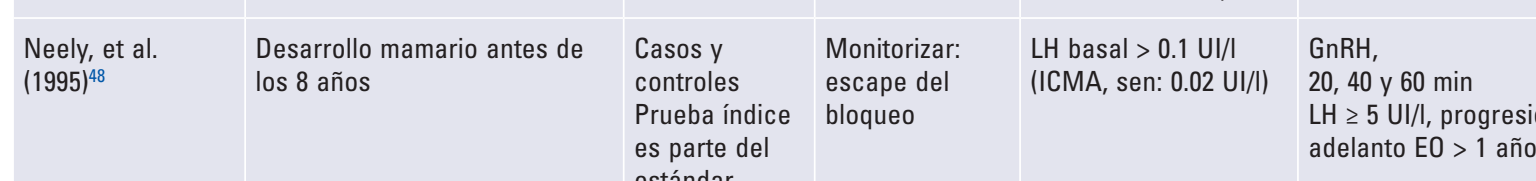

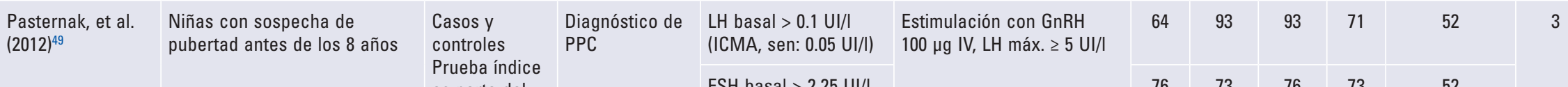

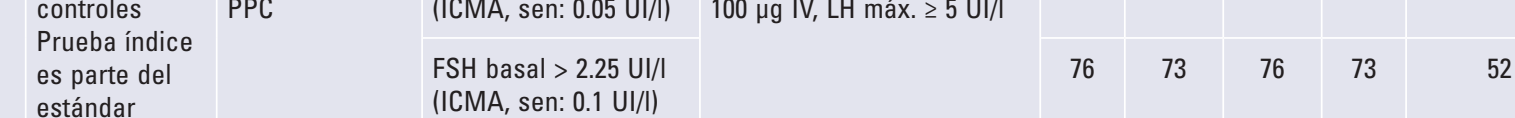

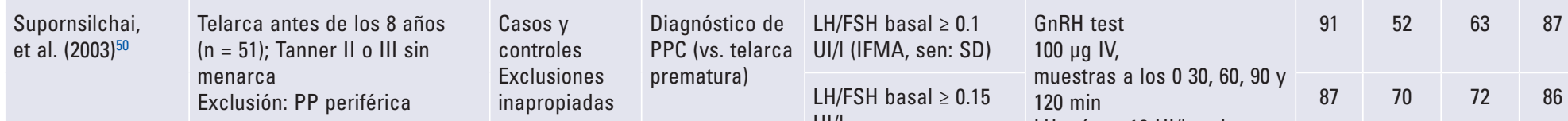

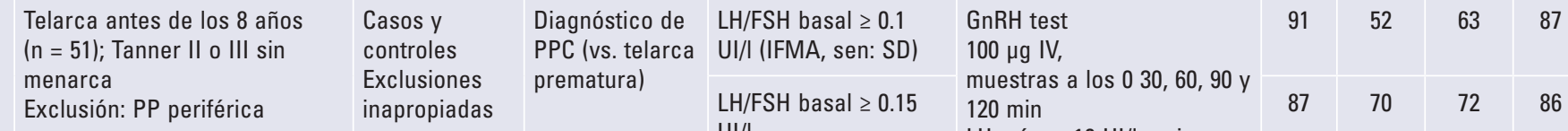

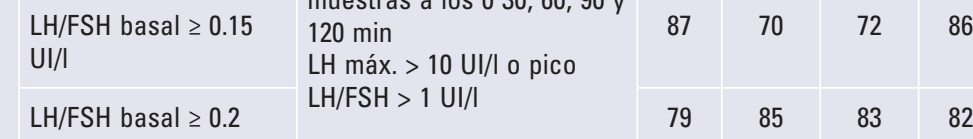
UH/III basal 20.2 LHFFH 20.3 UII

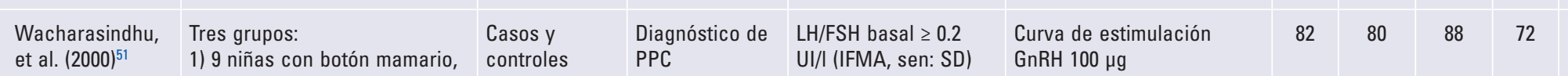

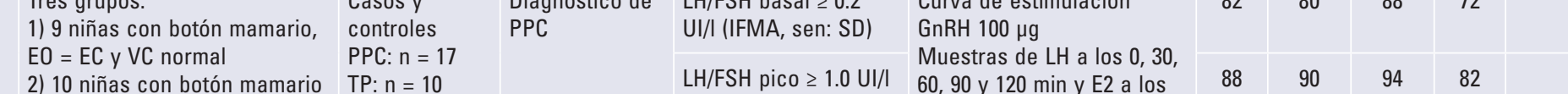

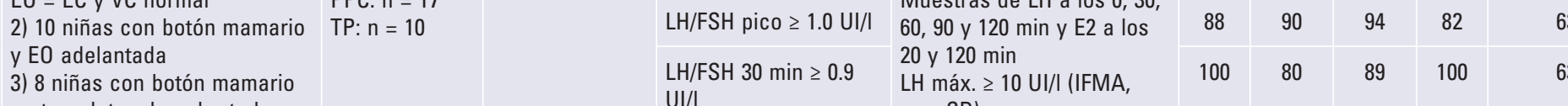

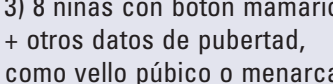

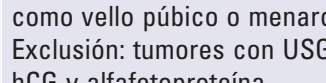


Tabla 8. Estudios de exactitud diagnóstica para pubertad precoz central: prueba de estimulación con GnRH/aGnRH vs. evolución

\begin{tabular}{|c|c|c|c|c|c|c|c|c|c|c|c|}
\hline Autor (año) & Población & Diseño & Objetivo & Prueba índice & Estándar & $\begin{array}{l}\text { Sen } \\
(\%)\end{array}$ & $\begin{array}{l}\text { Esp } \\
(\%)\end{array}$ & $\begin{array}{l}\text { YPP } \\
(\%)\end{array}$ & $\begin{array}{l}\text { VPN } \\
(\%)\end{array}$ & $\begin{array}{c}\text { Probabilidad } \\
\text { preprueba (\%) }\end{array}$ & Calidad \\
\hline \multirow[t]{2}{*}{$\begin{array}{l}\text { Calcaterra, } \\
\text { et al. (2009) }\end{array}$} & \multirow[t]{2}{*}{$\begin{array}{l}60 \text { niñas de 3-8 años con } \\
\text { caracteres sexuales } \\
\text { secundarios } \\
\text { Sin manifestaciones } \\
\text { neurológicas ni exposición a } \\
\text { andrógenos } \\
\text { Tanner II ( } n=27) \text {, Tanner III } \\
(n=30) \text {, Tanner IV }(n=3)\end{array}$} & \multirow[t]{2}{*}{$\begin{array}{l}\text { Cohorte prolectiva, } \\
\text { casoss } \\
\text { consecutivos }\end{array}$} & $\begin{array}{l}\text { PPC } \\
\text { rápidamente } \\
\text { progresiva } \\
\text { (n }=25 \text { ) vs. PP } \\
\text { lentamente } \\
\text { progresiva } \\
(n=32)\end{array}$ & $\begin{array}{l}\text { Estimulación con GnRH, } \\
\text { LH máx. } 27 \text { UI// (ICMA, sen: SD) }\end{array}$ & \multirow{2}{*}{$\begin{array}{l}\text { Evolución tras } \\
\text { seguimiento de al } \\
\text { menos } 6 \text { meses } y \\
\text { presentación de al } \\
\text { menos uno de los } \\
\text { siguientes: } \\
\text { - Menarca } \\
\text { - Pubarca } \\
\text { - Aceleración de E0 } \\
\text { o VC }>2 \text { DE (no son } \\
\text { claras las } \\
\text { definiciones) }\end{array}$} & 88 & 100 & 100 & 91 & 44 & 2 \\
\hline & & & $\begin{array}{l}\text { PPC } \\
\text { rápidamente } \\
\text { progresiva } \\
\text { (n=24) vs. PP } \\
\text { lentamente } \\
\text { progresiva } \\
(\mathrm{n}=34) .\end{array}$ & E2 z 50 pmol// (ICMA, sens: SD). & & 58 & 79 & 67 & 73 & 41 & \\
\hline \multirow[t]{7}{*}{$\begin{array}{l}\text { Carretto, et al. } \\
(2014)^{53}\end{array}$} & \multirow{7}{*}{$\begin{array}{l}\text { Niñas con Tanner } \geq \| \text { antes de } \\
\text { los } 8 \text { años }(7.15-7.38 \text { años) sin } \\
\text { otras enfermedades crónicas ni } \\
\text { endocrinológicas } \\
\text { Tanner II }(n=24) \text {, } \\
\text { Tanner III ( }=4) \\
\text { Exclusión: si solo pubarca } \\
\text { precoz aislada } \\
\text { Eliminación: si no completaron } \\
12 \text { meses de seguimiento }\end{array}$} & \multirow{7}{*}{$\begin{array}{l}\text { Cohorte } \\
\text { retrolectiva } \\
\text { No indica cuántas } \\
\text { se perdieron en el } \\
\text { seguimiento }\end{array}$} & \multirow{7}{*}{$\begin{array}{l}\text { Pubertad } \\
\text { progresiva } \\
\text { (n = 28) vs. } \\
\text { no progresiva } \\
(\mathrm{n}=33 \text { ) }\end{array}$} & $\begin{array}{l}\text { LH basal > } 0.1 \text { UI// (ICMA, sen: } \\
0.1 \text { U//I) }\end{array}$ & \multirow{7}{*}{$\begin{array}{l}\text { Evolución: } \\
\text { crecimiento } \\
\text { mamario, } \\
\text { aceleración de VC, } \\
\text { progresión de } \mathrm{EO} \text { en } \\
\text { los primeros } 6 \text { meses } \\
\text { de seguimiento }\end{array}$} & 71 & 94 & 91 & 79 & \multirow[t]{7}{*}{46} & \multirow[t]{7}{*}{3} \\
\hline & & & & LH basal > $0.8 \mathrm{U} / / \mathrm{I}$ & & 46 & 100 & 100 & 69 & & \\
\hline & & & & $\begin{array}{l}\text { LH } 3 \mathrm{~h} \text { tras estímulo con } 0.5 \mathrm{mg} \\
\text { leuprorelina SC acuoso }>5.5 \mathrm{U} / / /\end{array}$ & & 93 & 100 & 100 & 94 & & \\
\hline & & & & $\begin{array}{l}\text { E2 basal > } 12 \text { pg/ml (ICMA, sen: } \\
12 \text { pg/m/l) }\end{array}$ & & 64 & 88 & 82 & 74 & & \\
\hline & & & & E2 $24 \mathrm{~h}$ tras estímulo $>79.6 \mathrm{mg} / \mathrm{dl}$ & & 75 & 97 & 95 & 82 & & \\
\hline & & & & $\begin{array}{l}\text { LH/FSH basal > } 0.23 \text { UI// (ICMA, } \\
\text { sen: } 0.1 \text { UI/I) }\end{array}$ & & 53 & 97 & 94 & 71 & & \\
\hline & & & & LH/FSH tras estímulo > $0.24 \mathrm{UI/I}$ & & 100 & 94 & 93 & 100 & & \\
\hline \multirow[t]{3}{*}{$\begin{array}{l}\text { Chen, et al. } \\
(20077)^{54}\end{array}$} & \multirow{3}{*}{$\begin{array}{l}148 \text { niñas de } 5 \text { a } 8 \text { años con } \\
\text { Tanner II } \\
\text { Exclusión: anomalías del SNC, } \\
\text { obesidad, peso bajo o alto al } \\
\text { nacer } \\
\text { PPC idióáticica: } \mathrm{n}=83 \text { ( } 55 \\
\text { rápidamente progresiva } 28 \\
\text { lentamente progresiva) } \\
\text { TP: } \mathrm{n}=65 \\
\text { Controles Tanner I: } \mathrm{n}=20 \\
\text { PPC idiopática: LH tras estímulo } \\
>5 \text { UU/I, RM normal }\end{array}$} & \multirow{3}{*}{$\begin{array}{l}\text { Cohorte prolectiva } \\
\text { No se acclara qué } \\
\text { grupos incluyeron } \\
\text { en el análisis de } \\
\text { sensibilidad } y \\
\text { especificidad } \\
\text { Se asume que solo } \\
\text { al grupo de PP } \\
\text { rápidamente } \\
\text { progresiva ( } n=55) \\
\text { y lentamente } \\
\text { progresiva ( } n=28)\end{array}$} & \multirow{3}{*}{$\begin{array}{l}\text { Diagnóstico de } \\
\text { PPC } \\
\text { rápidamente } \\
\text { progresiva (vs. } \\
\text { PPC } \\
\text { lentamente } \\
\text { progresiva) } \\
\\
\end{array}$} & $\begin{array}{l}\text { LH basal > } 0.37 \text { UI// (ICMA, } \\
\text { sen: } 0.07 \text { U/I/I) }\end{array}$ & \multirow{3}{*}{$\begin{array}{l}\text { Dos o más criterios } \\
\text { durante seguimiento } \\
\text { por } 6 \text { meses: } \\
\text { progresión de } \\
\text { Tannerer progresión } \\
\text { de } E 0 \text { más de } 1 / 2 \\
\text { año, } \mathrm{ZVC} \geq 2\end{array}$} & 38 & 82 & 81 & 40 & \multirow[t]{3}{*}{66} & \multirow[t]{3}{*}{3} \\
\hline & & & & LH máx. > 8.4 UI/I & & 31 & 93 & 89 & 41 & & \\
\hline & & & & LH/FSH basal > $0.62 \mathrm{UI/I}$ & & 47 & 86 & 87 & 45 & & \\
\hline \multirow[t]{2}{*}{$\begin{array}{l}\text { Chin, et al. } \\
(2015)^{55}\end{array}$} & \multirow{2}{*}{$\begin{array}{l}\text { Niñas con botón mamario o } \\
\text { vello púbico antes de los } 7 \text { años } \\
\text { (caucásicasc o de los } 6 \text { años } \\
\text { (afroamericanas) } \\
\text { Exclusión: PP periférica o } \\
\text { tratamiento por problemas } \\
\text { puberales } \\
\text { PPC: } \mathrm{n}=20 \text { No PPC: } \mathrm{n}=15\end{array}$} & \multirow{2}{*}{$\begin{array}{l}\text { Cohorte } \\
\text { retrolectiva } \\
\text { No se indica } \\
\text { cuántos se } \\
\text { perdieron } \\
\text { Exclusiones } \\
\text { inapropiadas }\end{array}$} & \multirow[t]{2}{*}{$\begin{array}{l}\text { Diagnóstico } \\
\text { PPC vs. otros } \\
\text { (telarca o } \\
\text { adrenarca } \\
\text { prematura) }\end{array}$} & $\begin{array}{l}100 \mu \mathrm{g} \mathrm{GnRH} \mathrm{IV} \text {, incremento de } \\
\text { E2 } 24 \mathrm{~h} \mathrm{tras} \mathrm{estimulo} 27.8 \% \\
\text { sobre E2 } 3 \mathrm{~h} \\
\text { (ICMA, sen: } 15 \mathrm{pg} / \mathrm{ml} \text { ) }\end{array}$ & \multirow[t]{2}{*}{$\begin{array}{l}\text { Revisión de datos } \\
\text { por tres expertos a } \\
\text { los } 0,6 \text { y } 12 \text { meses } \\
\text { (datos clinicos, } \\
\text { laboratorios basales, } \\
\text { EO, VC, USG, RM) }\end{array}$} & 80 & 87 & 89 & 76 & \multirow[t]{2}{*}{57} & 3 \\
\hline & & & & $\begin{array}{l}\text { LH } 3 \mathrm{~h} \text { tras estímulo > } 5.06 \mathrm{UI/I} \\
\text { (ICMA, sen: } 0.05 \mathrm{UI} / / \text { ) }\end{array}$ & & 75 & 87 & 88.5 & 72 & & \\
\hline $\begin{array}{l}\text { De Vries, } \\
\text { et al. }(2006)^{56}\end{array}$ & $\begin{array}{l}\text { Niñas 4-8 años con Tanner } \\
\text { mamario II III } \\
\text { Exclusion de enfermedades }\end{array}$ & Cohorte & $\begin{array}{l}\text { Diagnóstico } \\
\text { PPC vs. TP }\end{array}$ & $\begin{array}{l}\text { GnRH } 100 \mu \mathrm{g} I \mathrm{~V} \text {, muestras } 0,30 \text { y } \\
60 \mathrm{~min} \\
\mathrm{LH}>5 \mathrm{U} \text { UI/ (ICMA, sen: } \mathrm{SD}) .\end{array}$ & $\begin{array}{l}\text { Criterios clínicos y } \\
\text { seguimiento, al } \\
\text { menos, por } 3 \text { años }\end{array}$ & 63 & 95 & 98 & 41 & 79 & 2 \\
\hline & TP: $n=22$ & & & Pico LH/pico FSH > 1 UI/I & & 36 & 100 & 100 & 30 & & \\
\hline $\begin{array}{l}\text { Haber, et al. } \\
(1995)^{4+4}\end{array}$ & $\begin{array}{l}\text { Cuatro grupos predefinidos: } \\
\text { TP }(n=55) \text {, PP temprana } \\
(n=11) \text { y avanzada }(n=9) \text { y } \\
\text { controles sanas }(n=101)\end{array}$ & Casos y controles & $\begin{array}{l}\text { Diagnóstico de } \\
\text { PPC }\end{array}$ & $\begin{array}{l}\text { Pico LH/FSH > } 1 \text { U/// (FSH, ICMA, } \\
\text { sen: } 0.1 \text { UI//) }\end{array}$ & $\begin{array}{l}\text { El diagnóstico ya } \\
\text { está predefinido, } \\
\text { pero los criterios no } \\
\text { son claros }\end{array}$ & 33 & 100 & 100 & 92 & 11 & 3 \\
\hline $\begin{array}{l}\text { Harrington, } \\
\text { et al. (2014) }\end{array}$ & $\begin{array}{l}\text { Niñas con botón mamario antes } \\
\text { de los } 8 \text { años } \\
\text { Exclusión: sisolo pubarca }\end{array}$ & $\begin{array}{l}\text { Cohorte } \\
\text { retrolectiva }\end{array}$ & $\begin{array}{l}\text { Diagnóstico } \\
\text { PPC progresiva } \\
\text { vs. no }\end{array}$ & 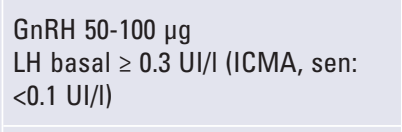 & $\begin{array}{l}\text { Desarrollo mamario } \\
\text { progresivo en los } 6 \\
\text { meses siguientes a }\end{array}$ & 89 & 100 & 100 & 95 & 32 & 3 \\
\hline & $\begin{array}{l}\text { SNC Y } 3 \text { con otras condiciones } \\
\text { de SNC }\end{array}$ & & & LH $50 \mathrm{~min}>5 \mathrm{UI} / \mathrm{I}$ & (1) & 94 & 90 & 81 & 97 & & \\
\hline $\begin{array}{ll}\text { Junqueira, } & \text { I } \\
\text { et al. }(2015)^{58} & \vdots\end{array}$ & $\begin{array}{l}\text { Niñas con caracteres sexuales } \\
\text { antes de los } 8 \text { años } \\
\text { Incluye pubarca aislada }\end{array}$ & $\begin{array}{l}\text { Cohorte prolectiva } \\
\text { No reporta } \\
\text { perdidas }\end{array}$ & $\begin{array}{l}\text { Diagnóstico de } \\
\text { PCP progresiva } \\
\text { vs. no }\end{array}$ & $\begin{array}{l}\text { Leuprorelina } 500 \mu \mathrm{gC} \\
\text { LH } 3 \mathrm{~h} \text { tras estimulo }>4 \mathrm{U} / / \mathrm{l} \\
\text { (ICMA, sen: } 0.05 \mathrm{U} / / /) \text { ) }\end{array}$ & $\begin{array}{l}\text { Evaluación a los } 6 \\
\text { meses: Tanner, E0, } \\
\text { VC }\end{array}$ & 73 & 83 & 81 & 76 & 50 & 3 \\
\hline & & & & LH $3 \mathrm{~h}>8.4 \mathrm{U} / / \mathrm{I}$ & No son muy claros & SD & 100 & SD & 100 & & \\
\hline & & & & $\begin{array}{l}\text { E2 } 24 \mathrm{~h}>52.9 \mathrm{pg} / \mathrm{ml} \text { (ICMA, sen: } \\
8 \mathrm{pg} / \mathrm{mll})\end{array}$ & los criterios & 68 & 74 & 72 & 70 & & \\
\hline $\begin{array}{l}\text { Pasternak, } \\
\text { et al. }(2012)^{49}\end{array}$ & $\begin{array}{l}\text { Niñas con sospecha de } \\
\text { pubertad antes de los } 8 \text { años }\end{array}$ & $\begin{array}{l}\text { Casos y controles } \\
\text { El estándar no es } \\
\text { claro: a las que } \\
\text { tenían prueba de } \\
\text { estimulación } \\
\text { positiva les daban } \\
\text { tratamiento } \\
\text { (estándar influido } \\
\text { por prueba índice) }\end{array}$ & $\begin{array}{l}\text { Diagnóstico de } \\
\text { PPC progresiva } \\
\text { vs. no } \\
\text { progresiva }\end{array}$ & $\begin{array}{l}\text { GnRH } 100 \text { ug IV, muestras a los } \\
15,30,45, y 60 \text { min } \\
\text { LH máx> } 4.9 \text { UI/I (ICMA, sen: } \\
0.05 \text { UI//I) }\end{array}$ & $\begin{array}{l}\text { Juicio de experto a } \\
\text { los } 2 \text { años }\end{array}$ & 78 & 79 & 80 & 76 & 52 & 3 \\
\hline $\begin{array}{l}\text { Poomthavorn, } \\
\text { et al. }(2009)^{59}\end{array}$ & $\begin{array}{l}101 \text { niñas con desarrollo } \\
\text { mamario antes de los } 8 \text { años }\end{array}$ & $\begin{array}{l}\text { Casos y controles } \\
\text { anidado en } \\
\text { cohorte } \\
\text { PPC idiopática: } \\
\text { n = 55 }\end{array}$ & $\begin{array}{l}\text { Diagnóstico de } \\
\text { PPC }\end{array}$ & $\begin{array}{l}\text { Triptorelina } 0.1 \text { mg SC } 10,30,60, \\
90 \text { y } 120 \text { min) } \\
\text { LH máx > } 6 \text { UI/I IICMA, sen: } 0.07 \\
\text { UI/I) }\end{array}$ & $\begin{array}{l}\text { Poco claro: datos } \\
\text { clinicos + USG (útero } \\
\text { piriforme con } \\
\text { endometrio } \\
\text { enarosado dímetro }\end{array}$ & 89 & 91 & 79 & 85 & 54 & 2 \\
\hline & & TP: $n=46$ & & LH basal > $0.1 \mathrm{UI/I}$ & $\begin{array}{l}>4 \mathrm{~cm}^{3}, \text { volumen } \\
\left.\text { ovario }>2 \mathrm{~cm}^{3}\right), \mathrm{VC} \text {, } \\
\text { EO }\end{array}$ & 76 & 80 & 82 & 74 & & \\
\hline $\begin{array}{ll}\text { Sathasivam, } & 3 \\
\text { et al. }(2010)^{60} & n \\
& \end{array}$ & $\begin{array}{l}39 \text { niñas }<8 \text { años con Tanner } \\
\text { mamario II o III } \\
\text { Exclusión: enfermedad orgánica } \\
\text { Más } 12 \text { niñas con pubarca } \\
\text { aislada y con prueba de } \\
\text { ectimulación }\end{array}$ & $\begin{array}{l}\text { Cohorte } \\
\text { retrolectiva } \\
\text { Pérdidas al } \\
\text { seguimiento: } 9\end{array}$ & $\begin{array}{l}\text { Diagnóstico de } \\
\text { PPC progresiva } \\
\text { vs. no } \\
\text { progresiva }\end{array}$ & 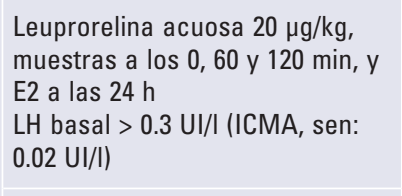 & $\begin{array}{l}\text { Evolución a los } 6 \\
\text { meses }\end{array}$ & 35 & 100 & 100 & 52 & 59 & 2 \\
\hline & & & & LH máx $\geq 5$ UI/I & & 78 & 100 & 100. & 76 & & \\
\hline & & & & $\begin{array}{l}\text { E2 basal } \geq 37 \mathrm{pmol} / /(10 \mathrm{pg} / \mathrm{mll}) \\
\text { (RIA, sen: } 3-5 \mathrm{ng} / \text {; y TMS, } \\
\text { sen: } 1 \mathrm{ng} / \mathrm{ll})\end{array}$ & & 39 & 100 & 100 & 53 & & \\
\hline & & & & E2 24 h $\geq 184$ pmol// (50 pg/ml) & & 84 & 100 & 100 & 82 & 58 & \\
\hline & & & & $\begin{array}{l}\text { LH > } 0.3 \mathrm{UI} / \mathrm{I} \\
\text { E2 basal } \geq 37 \mathrm{pmol} / \mathrm{I}\end{array}$ & & 48 & 100 & 100 & 57 & & \\
\hline & & & & $\begin{array}{l}\text { Pico LH } \geq 5 \text { UI// o pico E2 } \geq 184 \\
\text { pmol//I }\end{array}$ & & 100 & 100 & 100 & 100 & & \\
\hline $\begin{array}{l}\text { Freire, et al. } \\
(2013)^{43}\end{array}$ & $\begin{array}{l}\text { Niñas } 4-8.5 \text { años con telarca y } \\
\text { VC }>\text { p90, adelanto EO }>1.5 \\
\text { años } \\
\text { PPC: } n=33 \\
\text { TP: } n=13\end{array}$ & $\begin{array}{l}\text { Cohorte prolectiva } \\
\text { Aleatorización de } \\
\text { la secuencia de } \\
\text { prueba índice y } \\
\text { estándar }\end{array}$ & $\begin{array}{l}\text { Diagnóstico de } \\
\text { PPC }\end{array}$ & $\begin{array}{l}\text { Triptorelina SC } 0.1 \mathrm{mg} / \mathrm{m}^{2} \\
\text { muestras a los } 0 \mathrm{~min}, 3 \mathrm{~h} \text { y } 24 \mathrm{~h} \\
\mathrm{LH} 3 \mathrm{~h} \text { (IFMA } 7 \mathrm{U} / / / ; \text { sen: } 0.05 \\
\text { UI/I) }\end{array}$ & $\begin{array}{l}\text { GnRH } 100 \mu \mathrm{g} / \mathrm{m}^{2}, \\
\text { muestras a los } 0,30 \\
\text { y } 60 \text { min } \\
\text { LH máx } \geq 6 \text { UI/I + } \\
\text { seguimiento hasta }\end{array}$ & 76 & 100 & 100 & 61 & 72 & 1 \\
\hline & & & & $\mathrm{LH} 3 \mathrm{~h}$ (EQLL > $8 \mathrm{U} / ;$; sen: $0.1 \mathrm{U} / \mathrm{l} / \mathrm{)}$ & los 9 años & 76 & 100 & 100 & 61 & & \\
\hline & & & & $\begin{array}{l}\text { E2 } 24 \mathrm{~h}>295 \mathrm{pmol} / \mathrm{l}(80 \mathrm{pg} / \mathrm{mll}) \\
\text { (EQL, sen: } 36.7 \mathrm{pm})\end{array}$ & & 79 & 100 & 100 & 65 & & \\
\hline & & & & LH $3 \mathrm{~h} \mathrm{IFMA} \mathrm{o} \mathrm{E2} 24 \mathrm{~h}$ & & 94 & 100 & 100 & 87 & & \\
\hline & & & & LH $3 \mathrm{~h} \mathrm{EQL} \mathrm{o} \mathrm{E2} 24 \mathrm{~h}$ & & 94 & 100 & 100 & 87 & & \\
\hline $\begin{array}{l}\text { Zung, et al. } \\
\text { (2014) }\end{array}$ & $\begin{array}{l}\text { Niñas con sospecha de PP } \\
(n=62) \text {; telarca a los 3-8 años } \\
\text { Exclusión: enuresis, HSC, PP } \\
\text { perífirica, } 15 \text { niñas con } L H>10 \\
\text { UI/I que iniciaron aGnRH } \\
\text { Al final se analizaron } 47 \text { niñas }\end{array}$ & $\begin{array}{l}\text { Cohorte prolectiva } \\
\text { Exclusiones } \\
\text { inapropiadas }\end{array}$ & $\begin{array}{l}\text { PPC } \\
\text { rápidamente } \\
\text { progresiva vs. } \\
\text { lentamente } \\
\text { progresiva }\end{array}$ & 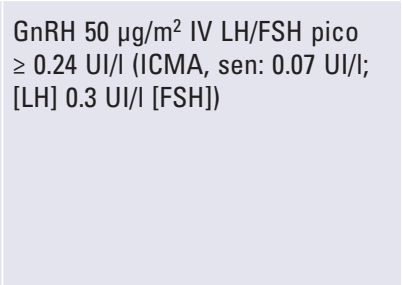 & $\begin{array}{l}\text { Evolución en } \\
6 \text { meses: } \\
\text { progresión de Tanner } \\
\text { mamario, VC }>2 D E \\
\text { y avance EO/EC }>1 \\
\text { (PP rápidamente } \\
\text { progresiva si dos o } \\
\text { más criterios) }\end{array}$ & 72 & 72 & 61 & 81 & 38 & 2 \\
\hline
\end{tabular}


Tabla 9. Estudios de exactitud diagnóstica para pubertad precoz central: ultrasonido

\begin{tabular}{|c|c|c|c|c|c|c|c|c|c|c|c|}
\hline Autor (año) & Población & Diseño & Objetivo & Prueba índice a evaluar & Estándar & $\begin{array}{l}\text { Sen } \\
(\%)\end{array}$ & $\begin{array}{l}\text { Esp } \\
(\%)\end{array}$ & $\begin{array}{l}\text { VPP } \\
(\%)\end{array}$ & $\begin{array}{l}\text { VPN } \\
(\%)\end{array}$ & $\begin{array}{l}\text { Probabilidad } \\
\text { preprueba (\%) }\end{array}$ & Calidad \\
\hline \multirow[t]{8}{*}{$\begin{array}{l}\text { Badouraki, } \\
\text { et al. }(2008)^{62}\end{array}$} & \multirow[t]{4}{*}{$\begin{array}{l}\text { Niñas con telarca/pubarca antes de } \\
\text { los } 8 \text { años + niñas sanas } \\
\text { Exclusión: anomalías en SNC, tumores } \\
\text { productores de hormonas sexuales } \\
\text { y HSC } \\
0-6 \text { años ( } n=27 \text { ) }\end{array}$} & \multirow[t]{8}{*}{$\begin{array}{l}\text { Casos y controles } \\
\text { Inclusión } \\
\text { inapropiada de } \\
\text { niñas sanas y } \\
\text { exclusiones } \\
\text { inapropiadas }\end{array}$} & \multirow[t]{8}{*}{$\begin{array}{l}\text { PPC vs. } \\
\text { pubarca } 0 \\
\text { TP }\end{array}$} & $\begin{array}{l}\text { USG } \\
\text { Longitud de útero } \geq 3.185 \mathrm{~cm}\end{array}$ & \multirow[t]{8}{*}{$\begin{array}{l}\text { GnRH IV } 2.5 \mu \mathrm{g} / \mathrm{kg} \text {, } \\
\text { muestras a los } 0,30 \text { y } \\
60 \text { min } \\
\text { LH máx. }>25 \mathrm{UI} / \mathrm{I} 0 \\
\text { LH máx./FSH máx. }>1 \\
\text { UI/I }\end{array}$} & 86 & 92 & 75 & 957 & 26 & 3 \\
\hline & & & & Volumen de útero $\geq 2.985 \mathrm{~cm}^{3}$ & & 86 & 75 & 54 & 94 & & \\
\hline & & & & Volumen ovárico $\geq 0.603 \mathrm{~cm}^{3}$ & & 86 & 75 & 54 & 947 & & \\
\hline & & & & $\begin{array}{l}\text { Longitud de fondo/cuerpo } \\
\text { uterino } \geq 1.05 \mathrm{~cm}\end{array}$ & & 71 & 67 & 42 & 87 & & \\
\hline & \multirow[t]{4}{*}{$6-8$ años $(n=35)$} & & & Longitud de útero $\geq 3.83 \mathrm{~cm}$ & & 82 & 91 & SD & SD & SD & \\
\hline & & & & Volumen de útero $\geq 3.35 \mathrm{~cm}^{3}$ & & 88 & 72 & SD & SD & SD & \\
\hline & & & & Volumen ovárico $\geq 1.9 \mathrm{~cm}^{3}$ & & 76 & 64 & SD & SD & SD & \\
\hline & & & & $\begin{array}{l}\text { Longitud de fondo/cuerpo } \\
\text { uterino } \geq 1.05 \mathrm{~cm}\end{array}$ & & 82 & 82 & SD & SD & SD & \\
\hline \multirow[t]{2}{*}{$\begin{array}{l}\text { Battaglia, } \\
\text { et al. }(2002)^{63}\end{array}$} & \multirow[t]{2}{*}{$\begin{array}{l}29 \text { niñas con desarrollo mamario y } \\
\text { vello púbico antes de los } 8 \text { años } \\
\text { Exclusión: diagnóstico que cursa con } \\
\text { desarrollo sexual independiente de } \\
\text { gonadotropinas, TP y pubarca } \\
\text { prematura }\end{array}$} & \multirow[t]{2}{*}{$\begin{array}{l}\text { Casos y controles } \\
\text { PPC: } n=20 \\
\text { "Respuesta } \\
\text { prepuberal»: } n=9\end{array}$} & \multirow[t]{2}{*}{$\begin{array}{l}\text { Diagnóstico } \\
\text { de PPC }\end{array}$} & $\begin{array}{l}\text { Doppler: índice de pulsatilidad } \\
\text { de arterias uterinas }<2.5 \\
\text { Volumen uterino } \geq 4 \mathrm{~cm}^{3}\end{array}$ & \multirow{2}{*}{$\begin{array}{l}100 \mu \mathrm{g} \mathrm{GnRH} \text { IV }(0,30, \\
60 \text { y } 90 \mathrm{~min}) \\
\text { Positivo: } \\
\text { LH basal }>0.3 \mathrm{UI} / / \mathrm{l} 0 \\
\text { LH máx. }>15 \mathrm{UI} / \mathrm{I} 0 \\
\text { LH/FSH > } 0.6 \mathrm{UI} / / \mathrm{I} 0 \\
\text { LH máx.-basal > } 7 \mathrm{UI} / \mathrm{I}\end{array}$} & 86 & 100 & 100 & 76 & 69 & 3 \\
\hline & & & & Eco endometrial & & 56 & 80 & 0 & 26 & & \\
\hline \multirow[t]{2}{*}{$\begin{array}{l}\text { Battaglia, et } \\
\text { al. }(2003)^{64}\end{array}$} & \multirow{2}{*}{$\begin{array}{l}29 \text { niñas con desarrollo mamario y } \\
\text { vello púbico antes de los } 8 \text { años } \\
\text { Exclusión: diagnóstico que cursa con } \\
\text { desarrollo sexual independiente de } \\
\text { gonadotropinas, TP y pubarca } \\
\text { prematura (siete sujetos repetidos de } \\
\text { Batagglia, et al., 2002 }\end{array}$} & \multirow[t]{2}{*}{$\begin{array}{l}\text { Casos y controles } \\
\text { PPC: } n=20 \\
\text { «Respuesta } \\
\text { prepuberal»: } n=9\end{array}$} & \multirow[t]{2}{*}{$\begin{array}{l}\text { Diagnóstico } \\
\text { de PPC }\end{array}$} & $\begin{array}{l}\text { Doppler: índice de pulsatilidad } \\
\text { de arterias uterinas }>2.5\end{array}$ & \multirow[t]{2}{*}{$\begin{array}{l}100 \mu \mathrm{g} \text { GnRH IV }(0,30, \\
60 \text { y } 90 \mathrm{~min}) \\
\text { Positivo: } \\
\text { LH basal }>0.3 \mathrm{UI} / \mathrm{I} 0 \\
\text { LH máx. }>15 \mathrm{UI} / \mathrm{I} 0 \\
\text { LH/FSH }>0.6 \mathrm{UI} / \mathrm{I} 0 \\
\text { LH máx.-basal > } 7 \mathrm{UI} / \mathrm{I}\end{array}$} & 94 & 96 & 88 & 98 & 25 & 3 \\
\hline & & & & Eco endometrial & & 87 & 86 & 67 & 95 & & \\
\hline \multirow[t]{3}{*}{$\begin{array}{l}\text { Binay, et al. } \\
(2014)^{37}\end{array}$} & \multirow{3}{*}{$\begin{array}{l}\text { Niñas con botón mamario antes de los } \\
8 \text { años } \\
\text { Exclusión (15/115): hiperestrogenemia } \\
\text { por obesidad, McCune-Abright, HSC, } \\
\text { antecedente de radioterapia de } \\
\text { cráneo } \\
\text { Edad de aparición de caracteres } \\
\text { sexuales secundarios: } 6.75 \pm 1.5 \text { años } \\
\text { PPC: } n=63 \\
\text { TP: } n=37\end{array}$} & & \multirow[t]{3}{*}{$\begin{array}{l}\text { Diagnóstico } \\
\text { de PPC }\end{array}$} & Longitud uterina $\geq 30 \mathrm{~mm}$ & \multirow{3}{*}{$\begin{array}{l}100 \mu \mathrm{g} \text { GnRH IV }(0,20, \\
40,60 \text { y } 90 \text { min) más } \\
\text { botón mamario, } \\
\text { adelanto } \mathrm{EO}>1 \text { año } \\
\text { LH máx. } 25 \mathrm{UI} / / \\
\text { LH/FSH máx. }>1 \mathrm{UI} / / \mathrm{o} \\
\text { LH basal }>0.3 \mathrm{UI} / \mathrm{I}\end{array}$} & 93 & 87 & 94 & 89 & 63 & 3 \\
\hline & & & & Volumen ovárico $\geq 1.3 \mathrm{~cm}^{3}$ & & 72 & 90 & 92 & 65 & & \\
\hline & & & & Relación fondo/cérvix $\geq 0.98$ & & 92 & 87 & 92 & 86 & & \\
\hline \multirow[t]{4}{*}{$\begin{array}{l}\text { Calcaterra, } \\
\text { et al. }(2009)^{52}\end{array}$} & \multirow[t]{4}{*}{$\begin{array}{l}60 \text { niñas de } 3-8 \text { años con desarrollo } \\
\text { de caracteres sexuales secundarios } \\
\text { Sin manifestaciones neurológicas ni } \\
\text { exposición a andrógenos o estrógenos } \\
\text { PP rápidamente progresiva: } n=25 \\
\text { PP lentamente progresiva: } n=35\end{array}$} & \multirow[t]{4}{*}{ Casos y controles } & \multirow[t]{4}{*}{$\begin{array}{l}\text { Diagnóstico } \\
\text { de PP } \\
\text { rápidamente } \\
\text { progresiva }\end{array}$} & USG: volumen uterino $\geq 5 \mathrm{~cm}^{3}$ & \multirow{4}{*}{$\begin{array}{l}\text { Evolución posterior, } \\
\text { seguimiento } \geq 6 \\
\text { meses } \\
\text { Rápidamente } \\
\text { progresiva: menarca, } \\
\text { pubarca, aceleración } \\
\text { de } V C \text { o EO > } 2 \text { DE (no } \\
\text { es claro) }\end{array}$} & 52 & 80 & 65 & 70 & 42 & 2 \\
\hline & & & & USG: eco endometrial & & 64 & 74 & 64 & 74 & & \\
\hline & & & & $\mathrm{EO}>2 \mathrm{DE}$ & & 72 & 74 & 67 & 79 & & \\
\hline & & & & USG mama $>0.85 \mathrm{~cm}^{3}$ & & 66 & 62 & 56 & 71 & & \\
\hline \multirow[t]{6}{*}{$\begin{array}{l}\text { De Vries, et } \\
\text { al. }(2006)^{56}\end{array}$} & \multirow{6}{*}{$\begin{array}{l}\text { Tanner II o III entre los } 4 \text { y los } 8 \text { años } \\
\text { de edad } \\
\text { Exclusión de enfermedades }\end{array}$} & Cohorte & Diagnóstico & Eco endometrial & GnRH $100 \mu \mathrm{g} \mathrm{IV}$ & 57 & 100 & 100 & 41 & 79 & 2 \\
\hline & & & & $\begin{array}{l}\text { Diámetro transverso útero } \\
>1.5 \mathrm{~cm}\end{array}$ & 60 min & 68 & 100 & 100 & 44 & & \\
\hline & & & & Fondo $>0.8 \mathrm{~cm}$ & $\begin{array}{l}\text { criterios clínicos y } \\
\text { seguimiento al menos }\end{array}$ & 82 & 76 & 93 & 54 & & \\
\hline & & & & Longitud útero > $3.4 \mathrm{~cm}$ & por 3 años & 89 & 89 & 97 & 68 & & \\
\hline & & & & Volumen uterino $>2 \mathrm{~cm}^{3}$ & & 89 & 89 & 97 & 68 & & \\
\hline & & & & $\begin{array}{l}\text { Circunferencia ovario } \\
>4.5 \mathrm{~cm}\end{array}$ & & 67 & 86 & 94 & 41 & & \\
\hline $\begin{array}{l}\text { Eksioglu, } \\
\text { et al. }(2013)^{65}\end{array}$ & $\begin{array}{l}0-8 \text { años con precocidad sexual } \\
\text { PPC: } n=51\end{array}$ & Casos y controles & $\begin{array}{l}\text { Diagnóstico } \\
\text { de PPC }\end{array}$ & $\begin{array}{l}\text { USG: relación } \\
\text { fondo/cérvix > } 1\end{array}$ & $\begin{array}{l}\text { Datos clínicos }+\mathrm{zEO}> \\
2+\mathrm{zVC}>2+\end{array}$ & 29 & SD & SD & SD & 41 & 3 \\
\hline & $\begin{array}{l}\text { Adrenarca precoz: } \mathrm{n}=18 \\
\text { TP: } \mathrm{n}=56\end{array}$ & & & USG: eco endometrial & $\begin{array}{l}\text { LH máx. tras estímulo } \\
>5 \mathrm{UI} / \mathrm{l}\end{array}$ & 55 & SD & SD & SD & & \\
\hline & 8-10 años & & & $\begin{array}{l}\text { USG: relación } \\
\text { f ondo/cérvix }>1\end{array}$ & & 36 & SD & SD & SD & & \\
\hline $\begin{array}{l}\text { Haber, et al. } \\
(1995)^{44}\end{array}$ & $\begin{array}{l}\text { Cuatro grupos predefinidos: } \\
\text { TP: } n=55\end{array}$ & Casos y controles & $\begin{array}{l}\text { Diagnóstico } \\
\text { de PPC }\end{array}$ & Volumen uterino $>1.8 \mathrm{~cm}^{3}$ & $\begin{array}{l}\text { No son claros los } \\
\text { criterios }\end{array}$ & 100 & 100 & 100 & 100 & 20 & 3 \\
\hline & $\begin{array}{l}\text { PP temprana: } n=11 \\
\text { PP avanzada: } n=9\end{array}$ & & & Longitud. uterina > 36 mm & & 90 & 100 & 100 & 97 & & \\
\hline & Controles sanas: $\mathrm{n}=101$ & & & Volumen ovárico $>1.2 \mathrm{~cm}^{3}$ & & 82 & 95 & 81 & 95 & & \\
\hline
\end{tabular}

DE: desviación estándar; EO: edad ósea; Esp: especificidad; FSH: hormona estimulante del folículo; GnRH: hormona liberadora de gonadotropina; HSC: hiperplasia suprarrenal congénita; IV: intravenoso; LH: hormona luteinizante; 
Bol Med Hosp Infant Mex. 2020;77Supl(1)

Tabla 10. Estudios de exactitud diagnóstica para pubertad precoz central: datos clínicos

\begin{tabular}{|c|c|c|c|c|c|c|c|c|c|c|c|}
\hline Autor (año) & Población & Diseño & Objetivo & Prueba índice & Estándar & $\begin{array}{l}\text { Sen } \\
(\%)\end{array}$ & $\begin{array}{l}\text { Esp } \\
(\%)\end{array}$ & $\begin{array}{l}\text { VPP } \\
(\%)\end{array}$ & $\begin{array}{l}\text { VPN } \\
(\%)\end{array}$ & $\begin{array}{c}\text { Probabilidad } \\
\text { preprueba (\%) }\end{array}$ & Calidad \\
\hline $\begin{array}{l}\text { De Vries, et al. } \\
(2006)^{56}\end{array}$ & $\begin{array}{l}\text { Niñas de } 4-8 \text { años con Tanner mamario } \\
\text { II o III } \\
\text { Exclusión de enfermedades } \\
\text { PP: } n=81 \\
\text { TP: } n=22\end{array}$ & Cohorte & $\begin{array}{l}\text { Diagnóstico de } \\
\text { PPC vs. TP }\end{array}$ & Pubarca & $\begin{array}{l}\text { GnRH } 100 \mu \mathrm{g} \mathrm{IV} \text {, muestras a } \\
\text { los } 0,30 \text { y } 60 \mathrm{~min} \\
\text { LH máx. } 5 \mathrm{UI} / \mathrm{I} \text { más criterios } \\
\text { clínicos y seguimiento de al } \\
\text { menos } 3 \text { años }\end{array}$ & 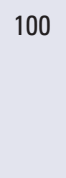 & 100 & 100 & 100 & 79 & 2 \\
\hline \multirow{5}{*}{$\begin{array}{l}\text { Junqueira, } \\
\text { et al. }(2015)^{58}\end{array}$} & \multirow{5}{*}{$\begin{array}{l}\text { Niñas con caracteres sexuales antes } \\
\text { de los } 8 \text { años; incluye pubarca aislada }\end{array}$} & \multirow{5}{*}{$\begin{array}{l}\text { Cohorte } \\
\text { prolectiva } \\
\text { No reporta } \\
\text { pérdidas }\end{array}$} & \multirow{5}{*}{$\begin{array}{l}\text { Diagnóstico de } \\
\text { PPC progresiva } \\
\text { vs. PPC no } \\
\text { progresiva }\end{array}$} & Telarca aislada & \multirow{5}{*}{$\begin{array}{l}\text { Evolución a } 6 \text { meses, } \\
\text { criterios clínicos }\end{array}$} & SD & SD & 37 & SD & SD & \multirow[t]{5}{*}{3} \\
\hline & & & & Pubarca aislada & & SD & SD & 50 & SD & SD & \\
\hline & & & & Telarca y pubarca & & SD & SD & 72 & SD & SD & \\
\hline & & & & $\begin{array}{l}\text { Telarca con o sin } \\
\text { pubarca }\end{array}$ & & 80.0 & 20 & 50 & 50 & \multirow[t]{2}{*}{50} & \\
\hline & & & & $\begin{array}{l}\text { Pubarca con o sin } \\
\text { telarca }\end{array}$ & & 63.3 & 63 & 63 & 63 & & \\
\hline $\begin{array}{l}\text { Zhu, et al. } \\
(2008)^{66}\end{array}$ & $\begin{array}{l}\text { Telarca prematura aislada a quienes se } \\
\text { descartó pubertad precoz } \\
\text { Aceleración de VC con LH estimulada } \\
<6.9 \text { UI/I, IGF-1 prepuberal, volumen } \\
\text { ovárico }<1 \mathrm{~cm}^{3} \text { y no quistes ováricos } \\
\geq 4 \mathrm{~mm} \text { en USG } \\
\text { Exclusión: causas secundarias } \\
\text { Edad: } 7.1 \pm 0.7 \text { años }(\mathrm{n}=151)\end{array}$ & Cohorte & Conversión a PPC & $\begin{array}{l}\text { No regresión de } \\
\text { tejido mamario }\end{array}$ & $\begin{array}{l}\text { Tamaño mamario con } \\
\text { crecimiento } \\
\text { Antes de los } 8 \text { años, } \\
\text { progresión de desarrollo } \\
\text { puberal y LH tras estímulo con } \\
\text { aGnRH > 6.9 UI/I durante el } \\
\text { seguimiento (ICMA, sen: SD) }\end{array}$ & "5 & 76 & 37 & 87 & 21 & 3 \\
\hline
\end{tabular}

aGnRH: agonistas de la hormona liberadora de gonadotropina; GnRH: hormona liberadora de gonadotropina; ICMA: inmunoquimioluminiscencia; IGF-1: factor de crecimiento similar a la insulina, tipo 1; IV: intravenoso; LH: hormona luteinizante; PP: pubertad precoz; PPC: pubertad precoz central; SD: sin datos; Sen: sensibilidad; TP: telarca prematura; USG: ultrasonido; VC: velocidad de crecimiento; VPN: valor predictivo हeegativo; VPP: valor predictivo positivo. 
María F. Castilla-Peón, et al.: Pubertad precoz: síntesis de la evidencia (Anexo)

Tabla 11. Estudios de exactitud diagnóstica para pubertad precoz central: hormona antimulleriana e inhibina B

\begin{tabular}{|c|c|c|c|c|c|c|c|c|c|c|c|}
\hline Autor (año) & Población & Diseño & Objetivo & $\begin{array}{l}\text { Prueba índice a } \\
\text { evaluar }\end{array}$ & Estándar & $\begin{array}{l}\text { Sen } \\
(\%)\end{array}$ & $\begin{array}{l}\text { Esp } \\
(\%)\end{array}$ & $\begin{array}{l}\text { VPP } \\
(\%)\end{array}$ & $\begin{array}{l}\text { VPN } \\
(\%)\end{array}$ & $\begin{array}{l}\text { Probabilidad } \\
\text { preprueba (\%) }\end{array}$ & Calidad \\
\hline $\begin{array}{l}\text { Chen, et al. } \\
(2017)^{54}\end{array}$ & $\begin{array}{l}\text { Niñas de } 5-8 \text { años de edad con } \\
\text { sospecha de PP } \\
\text { Exclusión: anomalías en SNC, obesidad, } \\
\text { peso bajo o alto al nacer } \\
\text { Se incluyeron } 20 \text { niñas sanas } \\
\text { prepuberales y } 83 \text { niñas con PPC con } \\
\text { pico de LH > } 5 \text { UI/I ( } n=83 \text { ) }\end{array}$ & $\begin{array}{l}\text { Cohorte (no se } \\
\text { aclara si en el } \\
\text { análisis de ROC se } \\
\text { incluyeron las } 83 \\
\text { niñas con PPC o } \\
\text { las } 148 \text { niñas con } \\
\text { telarca y las } 20 \\
\text { niñas normales) }\end{array}$ & $\begin{array}{l}\text { Diagnóstico } \\
\text { diferencial entre } \\
\text { PP rápidamente } \\
\text { progresiva, PP } \\
\text { lentamente } \\
\text { progresiva y TP }\end{array}$ & $\begin{array}{l}\text { HAM }>2.69 \mathrm{pmol} / \mathrm{l}+ \\
\text { INH C > } 30.12 \mathrm{pg} / \mathrm{ml} \\
\text { (ELISA, sen: } 0.08 \mathrm{ng} / \mathrm{ml} \\
\text { [HAM] } / 2.6 \mathrm{pg} / \mathrm{ml}[\text { [INH]) }\end{array}$ & $\begin{array}{l}\text { PPC rápidamente } \\
\text { progresiva } \\
\text { Dos o más criterios } \\
\text { durante } 6 \text { meses de } \\
\text { seguimiento: } \\
\text { progresión de Tanner, } \\
\text { progresión de EO más } \\
\text { de } 1 \frac{2}{2} \text { año, zVC } \geq 2\end{array}$ & 80 & 89 & 94 & 69 & 66 & 3 \\
\hline \multirow[t]{2}{*}{$\begin{array}{l}\text { De Filippo, } \\
\text { et al. }(2013)^{42}\end{array}$} & \multirow{2}{*}{$\begin{array}{l}\text { Botón mamario antes de los 8-9 años } \\
\text { Exclusión: PPC secundaria y PP } \\
\text { periférica y USG de mala calidad ( } n=62 \text { ) }\end{array}$} & \multirow{2}{*}{$\begin{array}{l}\text { Casos y controles } \\
\text { Exclusiones } \\
\text { inapropiadas }\end{array}$} & \multirow{2}{*}{$\begin{array}{l}\text { Diagnóstico de } \\
\text { PPC progresiva } \\
\text { vs. formas no } \\
\text { progresivas }\end{array}$} & $\begin{array}{l}\text { INH B > } 20 \mathrm{pg} / \mathrm{ml} \\
\text { (ELISA, sen: } 7 \mathrm{pg} / \mathrm{ml} \text { ) }\end{array}$ & \multirow{2}{*}{$\begin{array}{l}\text { Prueba de GnRH: } \\
\text { LH máx. } \geq 7 \mathrm{UI} / \mathrm{I}+(\mathrm{EO} \\
\text { adelantada o longitud } \\
\text { del útero +volumen } \\
\text { ovárico) + RM normal }\end{array}$} & 60 & 89 & 84 & 69 & \multirow[t]{2}{*}{50} & \multirow[t]{2}{*}{3} \\
\hline & & & & $\begin{array}{l}\text { LH basal > } 0.2 \mathrm{UI} / \mathrm{I}+ \\
\text { INH B > } 20 \mathrm{pg} / \mathrm{ml} \\
\text { (LH: ICMA, sen: } 0.1 \mathrm{UI} / \mathrm{l})\end{array}$ & & 98 & 99 & 99 & 98 & & \\
\hline
\end{tabular}

ELISA: enzyme-linked immunosorbent assay (ensayo por inmunoabsorción ligado a enzimas); EO: edad ósea; Esp: especificidad; GnRH: hormona liberadora de gonadotropina; HAM: hormona antimulleriana; ICMA: inmunoquimioluminiscencia; INH: inhibina; LH: hormona luteinizante; PP: pubertad precoz; PPC: pubertad precoz central; RM: resonancia magnética; ROC: receiver operating characteristics; Sen: sensibilidad; SNC: sistema nervioso central; TP: telarca prematura; VC: velocidad de crecimiento; VPN: valor predictivo negativo; VPP: valor predictivo positivo. 
Bol Med Hosp Infant Mex. 2020;77Supl(1)

Tabla 12. Estudios de exactitud diagnóstica para pubertad precoz central: hormona luteinizante en orina

\begin{tabular}{|c|c|c|c|c|c|c|c|c|c|c|c|}
\hline Autor (año) & Población & Diseño & Objetivo & $\begin{array}{l}\text { Prueba índice a } \\
\text { evaluar }\end{array}$ & Estándar & $\begin{array}{l}\text { Sen } \\
(\%)\end{array}$ & $\begin{array}{l}\text { Esp } \\
(\%)\end{array}$ & $\begin{array}{l}\text { VPP } \\
(\%)\end{array}$ & $\begin{array}{l}\text { VPN } \\
(\%)\end{array}$ & $\begin{array}{c}\text { Probabilidad } \\
\text { preprueba (\%) }\end{array}$ & Calidad \\
\hline $\begin{array}{l}\text { Kolby, et al. } \\
(2017)^{67}\end{array}$ & $\begin{array}{l}\text { Niñas }<8 \text { años con Tanner } \\
\geq \mathrm{II}(\mathrm{n}=25)\end{array}$ & $\begin{array}{l}\text { No se indica el } \\
\text { punto de corte de } \\
\text { la prueba índice }\end{array}$ & $\begin{array}{l}\text { Diagnóstico de } \\
\text { PPC }\end{array}$ & $\begin{array}{l}\text { LH en primera orina de } \\
\text { la mañana (no dice } \\
\text { punto de corte) } \\
\text { (IFMA, sen: } 0.05 \mathrm{UI} / \mathrm{l})\end{array}$ & $\begin{array}{l}\text { GnRH } 100 \mu \mathrm{g} \mathrm{IV} \\
\text { LH } 30 \mathrm{~min}>5 \mathrm{UI} / \mathrm{I}\end{array}$ & 75 & 92 & 90 & 80 & 48 & 3 \\
\hline $\begin{array}{l}\text { Zung, et al. } \\
(2014)^{61}\end{array}$ & $\begin{array}{l}\text { Niñas con sospecha de PPC } \\
\text { (n = 62), telarca entre los } 3 \text { y } \\
\text { los } 8 \text { años } \\
\text { Se analizaron } 47 \text { sujetos } \\
\text { Exclusión: enuresis, HSC, PP } \\
\text { periférica, } 15 \text { niñas con LH > } \\
10 \text { UI/I que iniciaron aGnRH }\end{array}$ & Cohorte & $\begin{array}{l}\text { Diagnóstico de } \\
\text { PPC rápidamente } \\
\text { progresiva } 0 \\
\text { formas } \\
\text { lentamente } \\
\text { progresivas }\end{array}$ & $\begin{array}{l}\text { LH en primera orina de } \\
\text { la mañana } \geq 1.16 \mathrm{UI} / \mathrm{I} \\
\text { (ICMA, sen: } 0.07 \mathrm{UI} / / \text { ) }\end{array}$ & $\begin{array}{l}\text { Evolución en } 6 \text { meses: } \\
\text { progresión de Tanner } \\
\text { mamario, } \mathrm{VC}>2 \mathrm{DE} \text { y } \\
\text { avance EO/EC > } 1 \\
\text { Si dos o tres criterios, se } \\
\text { consideró rápidamente } \\
\text { progresiva }\end{array}$ & 83 & 72 & 65 & 87 & 38 & 2 \\
\hline
\end{tabular}

aGnRH: agonistas de la hormona liberadora de gonadotropina; DE: desviación estándar; EC: edad cronológica; E0: edad ósea; Esp: especificidad; GnRH: hormona liberadora de gonadotropina; HSC: hiperplasia suprarrenal congénita; ICMA: aGnRH: agonistas de la hormona liberadora de gonadotropina; DE: desviación estándar; EC: edad cronológica; EO: edad ósea; Esp: especificidad; GnRH: hormona liberadora de gonadotropina; HSC: hiperplasia suprarrenal congénita; ICMA:
inmunoquimioluminiscencia; IFMA: inmunofluorescencia; IV: intravenoso; LH: hormona luteinizante; PP: pubertad precoz; PPC: pubertad precoz central; Sen: sensibiildad; VC: velocidad de crecimiento; VPN: valor predictivo negativo; VPP: valor inmunoquimioluminisce
predictivo positivo. 
María F. Castilla-Peón, et al: Pubertad precoz: síntesis de la evidencia (Anexo)

Tabla 13. Estudios de exactitud diagnóstica para pubertad precoz central: otras pruebas

\begin{tabular}{|c|c|c|c|c|c|c|c|c|c|c|c|}
\hline Autor (año) & Población & Diseño & Objetivo & Prueba índice & Estándar & $\begin{array}{l}\text { Sen } \\
(\%)\end{array}$ & $\begin{array}{l}\text { Esp } \\
(\%)\end{array}$ & $\begin{array}{l}\text { VPP } \\
(\%)\end{array}$ & $\begin{array}{l}\text { VPN } \\
(\%)\end{array}$ & $\begin{array}{l}\text { Probabilidad } \\
\text { preprueba (\%) }\end{array}$ & Calidad \\
\hline $\begin{array}{l}\text { De Vries, et al. } \\
(2006)^{56}\end{array}$ & $\begin{array}{l}\text { Niñas de } 4-8 \text { años con } \\
\text { Tanner mamario II o III } \\
\text { Exclusión de enfermedades } \\
\text { PP: } n=81 \\
\text { TP: } n=22\end{array}$ & Cohorte & $\begin{array}{l}\text { Diagnóstico } \\
\text { de PPC vs. } \\
\text { TP }\end{array}$ & $\begin{array}{l}\text { Androstenediona > } 1 \\
\text { nmol// (método: SD) } \\
\text { zEO > +1 }\end{array}$ & $\begin{array}{l}\text { GnRH } 100 \mu \mathrm{g} \text { IV (muestras a } \\
\text { los } 0,30 \text { y } 60 \mathrm{~min} \text { ) } \\
\text { LH máx. > } 5 \mathrm{UI} / \mathrm{I} \text { más criterios } \\
\text { clínicos y seguimiento de al } \\
\text { menos } 3 \text { años }\end{array}$ & 59 & 81 & 90 & 45 & 79 & 2 \\
\hline $\begin{array}{l}\text { Haber, et al. } \\
(1995)^{44}\end{array}$ & $\begin{array}{l}\text { Grupos predefinidos: } \\
\text { TP: } n=19 \\
\text { PP temprana: } n=5\end{array}$ & $\begin{array}{l}\text { Casos y controles } \\
\text { predefinidos } \\
\text { Nada claro el método de } \\
\text { referencia ni los números }\end{array}$ & $\begin{array}{l}\text { Diagnóstico } \\
\text { de PPC vs. } \\
\text { TP }\end{array}$ & $\begin{array}{l}\text { Citología vaginal } \\
\text { (presencia de células } \\
\text { superficiales) }\end{array}$ & $\begin{array}{l}\text { GnRH } 100 \mu \mathrm{g} \text { IV (muestras a } \\
\text { los } 0,30 \text { y } 60 \mathrm{~min} \text { ) } \\
\text { LH máx. } 55 \mathrm{UI} / \mathrm{l} \text { más criterios } \\
\text { clínicos y seguimiento de al } \\
\text { menos } 3 \text { años }\end{array}$ & 60 & 63 & 30 & 86 & 21 & 3 \\
\hline
\end{tabular}

E0: edad ósea; Esp: especificidad; GnRH: hormona liberadora de gonadotropinas; LH: hormona luteinizante; PP: pubertad precoz; PPC: pubertad precoz central; Sen: sensibilidad; TP: telarca prematura; VPN: valor predictivo negativo; VPP: valor predictivo positivo. 